ECONOMIC GROWTH AND INCOME DISTRIBUTION

BY

MACARIO SCHETTINO YAÑEZ

APPROVED

SUPERVISOR

Leslie Young

University of Texas at Austin

Carlos Urzúa

ITESM/El Colegio de México

José Romero

ITESM/El Colegio de México 
ECONOMIC GROWTH AND INCOME DISTRIBUTION.

BY

MACARIO SCHETTINO YAÑEZ

\author{
A DISSERTATION SUBMITTED TO \\ INSTITUTO TECNOLOGICO Y DE ESTUDIOS SURERIORES DE MONTERREY \\ IN PARTIAL FULFILLMENT OF THE REQUIREMENTS \\ FOR THE DEGREE OF DOCTOR OF PHILOSOPHY
}

AUGUST, 1993 
ABSTRACT

ECONOMIC GROWTH AND INCOME DISTRIBUTION

by

MACARIO SCHETTINO YAÑEZ

SUPERVISING PROFESSOR: LESIIE YOUNG

Recent theoretical advances in economic growth theory and the empirical studies that followed suggest that it is possible to answer the question: "What is the relation between economic growth and income distribution?" In this dissertation, answers to this question are developed using a function that describes income distribution in a model of economic growth. The results are consistent with previous theoretical and empirical findings. In certain circumstances, income distribution will reduce the rate of growth; also, under other special circumstances, income redistributions may accelerate the economy. Finally, as a general statement, the less egalitarian the distribution of income, the lower the rate of optimal growth. 
ECONOMIC GROWTH AND INCOME DISTRIBUTION ............ ACKNOWLEDGMENTS ....................... iv

LIST OF ILLUSTRATIONS ....................

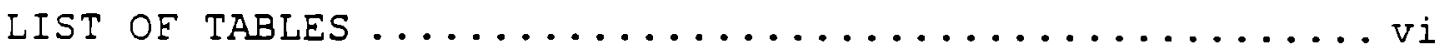
INTRODUCTION $\ldots \ldots \ldots \ldots \ldots \ldots \ldots \ldots \ldots \ldots \ldots \ldots \ldots$

PART I THE DESIRABILITY OF ECONOMIC GROWTH

CHAPTER 1 ECONOMIC GROWTH ................ 11

I. Economic Growth or Economic Development? .......... 11 . II. Economic Growth ..................... 17

CHAPTER 2 INCOME DISTRIBUTION .............. 33

I. Income Distribution Measurement ............. 33

II. Income Distribution and Demographic Factors ...... 38

III. Income Distribution and Economic Growth ........42

\section{PART II ECONOMIC GROWTH AND INCOME DISTRIBUTION}

CHAPTER 3 AN OVERLAPPING GENERATIONS MODEL .........45

I. The Model ........................... 45

II. Economic Equilibrium ..................47

III. Political Equilibrium ................. 48

IV. Dynamics of Growth .................... 50 
V. Minimal Consumption ..................... 51 CHAPTER 4 APPROXIMATING THE LORENZ CURVE ......... 57

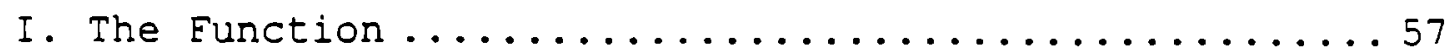

II. Empirical Results ....................60 III. Cross-Country and Time-Series ............. 64 CHAPTER 5 EXOGENOUS GROWTH AND INCOME DISTRIBUTION ....77 I. A Simple Model ...................... 77 II. Dynamics of Income Distribution $\ldots \ldots \ldots \ldots \ldots \ldots . \ldots 9$ III. Empirical results $\ldots \ldots \ldots \ldots \ldots \ldots \ldots \ldots \ldots \ldots$

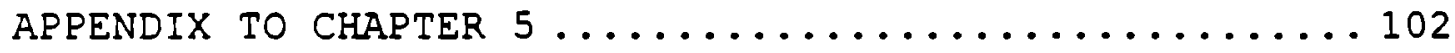
CHAPTER 6 ENDOGENOUS GROWTH AND INCOME DISTRIBUTION .. 104 CHAPTER 7 CONCLUSIONS ....................... 114

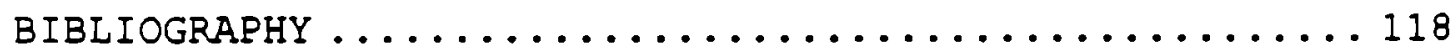




\section{LIST OF ILLUSTRATIONS}

Eigure

Figure 1.1. Technological Progress ..............21

Figure 2.1. Poverty and Income Distribution ........ 35

Figure 3.1. Minimal Consumption and Capital

Restriction .......................... 54

Figure 3.2. Amount of Poverty and minimal

redistribution tax $\ldots \ldots \ldots \ldots \ldots \ldots \ldots \ldots \ldots \ldots$

Eigure 4.1 . Lorenz curves .................. 74

Eigure 4.2. First Decile ................. 74

Figure 4.3. Middle of the curves ..............75

Figure 4.4. Top of the distribution ........... 75

Eigure 4.5. Absolute Residuals ..............76

Figure 4.6. Relative Residuals ...............76

Eigure 4.7. Relative Residuals .............. 77

Figure 5.1. Response of $\frac{\partial y^{i}}{\partial y}$ to a and b......... 92

Figure 5.2. $\mathbf{M}_{t}^{i}$ and Gini coefficient............ 97

Figure 5.3. Income Distribution and Growth .........98 98

Figure 5.4. Income Distribution and Growth ......... 99

Figure 5.5. Income and Distribution. Parameter $\alpha \ldots 102$

Figure 5.6. Income and Distribution. Parameter $\beta$... 102 


\section{LIST OF TABLES}

Table

Table 2.1 . Inequality Measures ............... 38

Table 4.1. Estimation Results and Comparison with

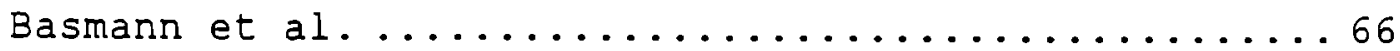

Table 4.1. Estimation Results and Comparison with

Basmann et al. (Cont.) ...................67

Table 4.1. Estimation Results and Comparison with

Basmann et al. (Cont.) ...................68

Table 4.2. Sum of Squared Residuals ............68

Table 4.3. Non-linear Regression results ..........69

Table 4.4 . Linear Regression results ...........69

Table 4.5. Robustness of Linear Regressions ........70

Table 4.6. Income Distribution Data for Cross-Country

study ................................

Table $4.7 . \alpha, \beta$ and $\gamma$ for different countries ...... 72

Table 4.8. Income Distribution Data for Mexico. 1950-

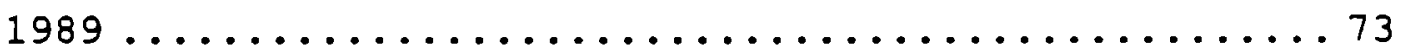

Table 4.9. $\alpha, \beta$ and $\gamma$ for Mexico ................. 73

Table 5.1 . Cross Country results ................. 101 
INTRODUCTION

The question of whether a country can experience economic growth and at the same time a better income distribution has been a major issue in the field of economic development. The arrival of the "new school" of economic growth, also called endogenous growth theory, gives us hope that the relationship between economic growth and income distribution may be better understood.

This dissertation has two main objectives. One, as stated in the title, is to find out more about the relationship between income distribution and economic growth. The other is to show that development economics can be much more than a collection of cases and experiences. My personal impression is that since development theory has not been able to formalize its hypotheses completelyl, its true importance has not been recognized (Bardhan, 1993). Many development theorists have believed that income inequality may slow the rate of

:With few, but very important, exceptions. 
growth of a country, but until recently, there has not been a theoretical effort to show this.

In this dissertation I will develop such a model and show that income distribution may indeed reduce or increase the rate of growth. This result is important since there is empirical evidence of both phenomena, as we shall see later. This thesis has the following structure. In the first two chapters I will review the work that has been done in this field. The first chapter is devoted to economic growth, while chapter 2 deals with income distribution.

The core of the dissertation is in chapters three to six. Chapter three presents a model of income distribution and economic growth developed by Persson and K Tabellini(1992) to which I incorporate a political feasibility condition, finding that inequality may be even more harmful than what they present. Then, in order to find a more formal and overwhelming way to analyze income distribution and economic growth, I develop in chapter four a function that fits the Lorenz curve and has some interesting theoretical and empirical properties. 
In chapter five I develop a model of economic growth including a function of income distribution that responds to changes in income. The solution to this model presents some interesting insights into the economic development process. Once we have found the way in which income distribution depends on the economic variables, we can describe the process that growth will follow, and it is possible to show that the less egalitarian the distribution, the lower the rate of growth. An important point of the model is that by including an income distribution function we are modeling reality in a better way than it was done before. In chapter six, the model is expanded to include human capital in order to explore more on the relation between distribution and growth.

The conclusions of this dissertation open many paths for future work on the study of the development process. Inequality is harmful for growth, and it is a result of institutions. Thus, institutions may be the most important determinants of growth. Surely, underdevelopment is not a matter of income only. 
PART I

THE DESIRABILITY OF ECONOMIC GROWTH 
CHAPTER 1

ECONOMIC GROWTH

This chapter deals with two issues. First, the difference between economic growth and economic development is stated, pointing out the issue that economic growth by itself may not be as useful as it was once thought. The second part of the chapter surveys recent advances in economic growth theory, the so called "new growth theory".

I. Economic Growth or Economic Development?

This is a very hard question. Maybe Robert Lucas has given the best answer:

Indeed, I suppose this is why we think of "growth" and "development" as distinct fields, with growth theory defined as those aspects of economic growth we have some understanding of, and development defined as those we don't. (Lucas, 1988, p.13).

It seems that economic growth should be a subset of economic development, since the focus of the former is on explaining how nations experience an increase in their per capita income, while the main issue of the latter is to 
explain why the quality of life varies greatly among rations. Economic growth focuses on explaining how ecoromic forces determine the rate of growth. Economic development asks why some people die of hunger while some others drink champagne and drive Jaguars.

A good operational definition of what is economic growth is given by Kuznets:

We gauge economic growth by the long-term rise in the volume and diversity of final goods, per capita, with some attention to sectorial structure and shifts; but exclude cases where such rise was due largely to natural resources made available by advanced technology elsewhere, or was attained in good part by intensified efforts of workers mobilized to involve a rising proportion of the population". (Kuznets, 1988, p.8)

Thus, only the increase in per capita production due to changes in productivity (either from capital of labor) may be called economic growth. Another issue is whether this increase in production is linked to an increase in welfare. This becomes more important the less developed the country of reference is. The issue here is if economic growth is really related to "happiness" or "better life" (Dasgupta, 1988, pp.5-8). The idea that more is preferable to less is not universally accepted now. (Herrick and Kindleberger, 1983, p.7). Even the idea of "growth at any 
cost" is not so appealling nowadays in the affluent countries, in light of ecological problems.

In fact, economic growth by itself seems not to be enough, as many countries have concluded in recent years. $C$. Ier and Katz report:

Economic growth in the $80^{\prime} \mathrm{s}$ in the U.S.A. is associated with less benefits for the poor. The change was on returns to skill, which represents less manufacturing employees. (Cutler and Katz, 1991, pp. 51-52)

This problem has been analyzed by Juhn, Murphy and Pierce (1993), who find that returns to skill in the U.S.A. grow. faster than returns to schooling, or any other determinant in wages. Growth, then, is not homogeneous for workers, increasing wage differentials and making less possible the promise that kuznets mentions:

It is plausible to argue that a major driving force in modern economic growth was the promise not only of greater material welfare but also of a more desirable organization of society that growth would, and does, make possible. (Kuznets, 1988, p.29)

It is really a controversy whether economic growth actually makes this reorganization of society possible. Dreze and Sen have their doubts:

Incurring the risk of oversimplifying, an increase in GNP per capita may give the opportunity of better 
quality of life. But that opportunity may be seized or not. (Dreze and Sen, 1989, p.181)

Not everything grows when income per capita grows. Some non-economic variables tend not to increase at the same pace as-income per capita. Literacy, for example, is positively related to economic growth, but this relation is far from perfect (Dasgupta, 1988, p.96). Cuba, for example, has reached almost no illiteracy with an income per capita far lower than the United States'. Dreze and Sen state:

Some non-economic variables determine that increases in real income may not increase fulfillment of basic needs. There are in principle two reasons for this dissonance (between GNP and life quality): GNP measures aggregate income, and its translation to quality of life will depend on income distribution. Second, the capabilities enjoyed by people depend on command over commodities, but also on public policies on health, education, etc. (Dreze and Sen, 1989, p. 178-180) [italics mine, MS].

Even in the case when income distribution becomes more egalitarian with growth, we cannot be sure that welfare has improved. Streeten et al. hold that:

Growth by itself -- even egalitarian growth or redistribution from growth -- does not guarantee the satisfaction of basic needs. A distinctive feature of the basic needs approach is that policies must be implemented to ensure a rising and properly distributed 
supply of goods, both private and public, if basic needs are to be met. (Streeten et al., 1981, p.108)

Basic needs differ from country to country, from region to region, even at an individual level we will have differences in what we consider to be basic needs (Dasgupta, 1988). For example, education may be, almost surely, a basic need in the United states or in England or Germany, while it is a luxury good in Haiti or Somalia.

Some authors even think that economic growth is associated to a cultural decline, something that we can not consider as "good" (Dasgupta, 1988, p.46). Ohmae. (1989), comparing Europe, United States and Japan, states that for incomes above 7,000 dollars, some similarities in preferences appear. Furthermore, cultural restrictions may prevent the enlargement of the production possibilities frontier; that is, some societies may opt not to grow in some instances, even if technology is available (Dasgupta, 1988, p.41). Similarly, Kuznets states that institutional problems may preclude some LCD's from development: land property, infrastructure, politics. He says

[...] While, in principle, all LCD's may be considered developable, it does not follow that they will become developed at some future date sufficiently close to matter. (Kuznets, 1989, p.72) 
Along these lines, Dreze and Sen (1989, p.183) hold tinat there are two approaches to increase general welfare: ore is "growth mediated security", in which increases in GNP per capita are followed by increases in real income and in public expenditure (absolute not relative) in public welfare programs. The other one is "support-led security", where the focus is on public policies like income redistribution, health, etc. Success is based on the reallocation of factors. They hold that "There is empirical evidence that support-led security is better in this sense", and use South Korea as an example of "support-led security". Mexico would be an example of "growth mediated security".

Support-led security is really growth with a better income distribution. Economic growth had its high time around the sixties, but nothing in this line was accomplished (Turnovsky, 1992). Now it is possible to build up a theory that includes something besides mere growth. Chenery et al. stated as early as 1974 that it is possible to grow and have a better distribution of income, at least the empirical side said so,

On the theoretical side, it is necessary to discard the conceptual separation between optimum growth and distribution policies that lies at the heart of 
traditional welfare economics. (Chenery et al., 1974, p.xiii)

Anyway, we should not need so many apologies for studying growth's relation to income distribution and for focusing on the poor. As $T$. Schultz noted in his Nobel Lecture in 1979,

[M] ost of the people in the world are poor, so if we! knew the economics of being poor we would know much of: the economics that really matters.

II. Economic Growth

Economic growth has been studied since the beginning of economy theory. It was a problem in the eighteenth century, and it is still a problem today. Attempts at solving this issue have been very different. In any case, the problem is still unsolved. Quite possibly, the period when economic growth became the problem in economics occurred between 1955 and 1970. At least two different approaches to understand growth collided in what is now called the Cambridge vs. Cambridge controversy.

Nevertheless, it was not until the mid-80's that economic growth started to be understood in its major 


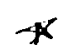

components. Before Romer's seminal paper on what is now called the "new growth theory," published in 1986, economic growth was explained mainly by exogenous factors like technological progress. The discussion, then, was sterile in the sense that no one was actually explaining growth, but trying to identify the way in which growth could be studied.

We can identify different approaches to economic growth, in terms of how they view the role of physical capital. One of these identifies capital as homogeneous, and builds an aggregate production function (Solow, 1976) The other one states that capital is not homogeneous, and rejects the possibility of having an aggregate function. The core of the Cambridge controversy lies here (Harcourt and Laing, 1977; Sen, 1979; Shaw, 1992). Agreement was impossible in the seventies, but it may be possible in the nineties. The "new growth theory" has, precisely, identified the endogenous force for growth in the heterogeneity of labor, knowledge, products, etc.

Let us start with Solow's model of growth'. He posits an aggregate production function of the form

:I will follow an argument similar to the one presented by Shaw (1992). 


$$
Y_{t}=A_{t} F\left(K_{t}, L_{t}\right)
$$

where national production is denoted by $Y_{t}, A_{t}$ is an index of overall productivity, technical level, etc. $K_{t}$ and $L_{t}$ are the inputs of capital and labo:, respectively. Differentiating (2.1), renders the rate at which the country will grow:

$$
\frac{\dot{Y}_{t}}{Y_{t}}=\frac{\dot{A}_{t}}{A_{t}}+\frac{\partial E\left(K_{t}, L_{t}\right)}{\partial L_{t}} \frac{\dot{L}_{t}}{Y_{t}}+\frac{\partial F\left(K_{t}, L_{t}\right)}{\partial K_{t}} \frac{\dot{K}_{t}}{Y_{t}}
$$

where the dot indicates a time derivative. If factors are paid according to their marginal productivity, becomes

$$
\frac{\dot{Y}_{t}}{Y_{t}}=\frac{\dot{A}_{t}}{A_{t}}+\frac{W L_{t}}{P Y_{t}} \frac{\dot{L}_{t}}{Y_{t}}+\frac{R K_{t}}{P Y_{t}} \frac{\dot{K}_{t}}{Y_{t}}
$$

where $W$ and $R$ are the labor and capital wages. But $W L_{t} / P Y_{t}$ is the labor share while $R K_{t} / P Y_{t}$ is the capital share of national product. Then, empirically, it is very easy to check that an increase in production, what we have called economic growth, can be produced by a similar increase in productivity (A), or by greater increases in labor or 
capital. In fact, Solow found that for the U.S.A. in the period 1900-1949, technical progress, that is, productivity increases, accounted for more than $85 \frac{3}{5}$ of the total increase in production. In short, exogenous technological advances explained more than 85 z growth.

We can understand this technological progress as an upward shift in the production function. Figure 2.1 presents this case. The important issue is to determine what caused this outward shift. Endogenous growth theory, the new growth theory, provides an answer to this question. Before going over them in detail, some definitions about growth may be important.

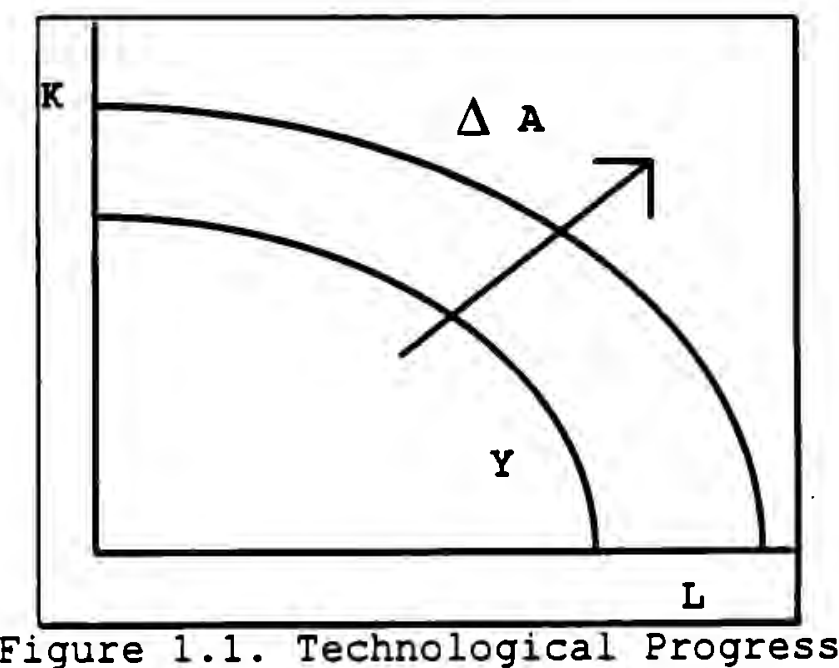


A two-fold division is often used to characterize the tipe of technological change. When technological progress is not associated with the inputs, it... is called "disembodied" progress. When, on the other hand, it affects production through the inputs, like new machines, "vintage" capital, etc., it is called "embodied" progress.

The other important point to be made about economic growth has to do with the capital/labor ratio. Technical progress is called "Hicks-neutral" if the marginal rate of substitution is unchanged as the progress goes on. In this case, if relative prices do not change, the capital/labor ratio will remain the same. That is the case of equation 2.1. If the progress is not Hicks-neutral, it is either capital-saving or labor-saving.

For each of them, another kind of neutrality has been defined. Harrod-neutrality occurs when the capital/output ratio is left unchanged and only labor is modified, this kind of neutrality would appear like

$$
Y_{t}=F\left(K_{t}, A_{t} L_{t}\right)
$$


The case of Solow-neutrality is the opposite, labor-output ratio is constant when technical progress goes on. This would be the case of

$$
Y_{t}=F\left(A_{t} K_{t}, L_{t}\right)
$$

In the mid-80's, an effort to understand better economic growth was initiated by Romer (1986), Lucas (1988) and others. The idea of Romer was that certain goods have increasing returns to production, although they present decreasing returns on its accumulation. This permits endogenous growth from the increasing returns. Nevertheless, the mere fact of having increasing returns will direct every agent in the economy towards its production. If the production of this good has decreasing returns, no matter what its importance in overall production, there will be a limit in the amount of resources devoted to its production. Thus, this characterisicic preserves the possibility of finding an equilibrium in the economy ${ }^{2}$ :

These tree elements--externalities, increasing returns in the production of output, and decreasing returns in the production of new knowledge--combine to produce a

-As we will see later, Lucas (1988) proposes a different alternative: a good that has constant returns on its accumulation, but for which individuals do not perceive the increasing returns to production, the so called external effect. 
well-specified competitive equilibrium model of growth. Despite the presence of increasing returns, a competitive equilibrium with externalitites will exist. This equilibrium is not Pareto optimal, but it is the cutcome of a well-behaved positive model and is capable cf explaining historical growth in the absence of government intervention [...] the key feature in the reversal of the standard results about growth is the assumption of increasing rather than decreasing marginal productivity of the intangible capital good knowledge. (Romer, 1936, pp. 1003-4)

Several variants of this original idea have been used. Some of these have their roots in Schumpeter (1944), although not everyone recognizes it. Among them, two approaches seem to be most important: Human capital and technology.

The human capital approach starts with Lucas (1988). He distinguishes two different effects of human capital on production: one is the normal effect that labor has; the other is the external effect, for which Lucas expresses the following:

I call this $\boldsymbol{h}_{a}$ effect external, because though all benefit from it, no individual human capital accumulation decision can have appreciable effect on $\boldsymbol{h}_{a}$, so no one will take it into account in deciding how to allocate his time. (Lucas, 1988, p.18)

The production function presented in Lucas (1988) is 


$$
Y_{t}=A k_{\imath}^{\theta} h_{\imath}^{1-\theta} h_{a}^{\mu}
$$

where $h$ denotes human capital, which along with physical capital gives this function constant returns to scale. $h_{\Delta}$ makes the difference since the outcome of this effect cannot be appropiated either by workers or by the firm, so it increases overall production.

Human capital is accumulated according to:

$$
\dot{h}=h \delta(1-u)
$$

where $u$ is the time devoted to production, the rest being used for human capital accumulation. $\delta$ is an efficiency parameter. This function doesn't exhibit diminishing returns, since as Iucas says, diminishing returns imply that

$\dot{h} / h$ must eventually tend to zero as $h$ grows no matter how much effort is devoted to accumulating it. This formulation would simply complicate the original solow model without offering any genuinely new possibilities. (op. cit. p. 19)

Using these two equations in a model of optimal growth, Lucas obtains a new model that he estimates with U.S. data and states: 
What can be concluded from these exercises? Normatively, it seems to me, very little: The model I have just described has exactly the same ability to fit U.S. data as does the solow model[...] I am simply yenerating new possibilities, in the hope of obtaining a tineoretical account of cross-country differences in income levels and growth rates. (op. cit. p.27)

A modification of this model includes "learning-bydoing", an idea of Arrow (1962) that Lucas includes in his model and which is also used later by stokey (1988), although in a new product framework. The point in learning-by-doing as opposed to the human capital version, is that efforts must be withdrawn from production of goods in order to produce human capital, while in learning-bydoing it is accumulated in the production process. Following this, (2.7) becomes

$$
\dot{h}=h \delta u
$$

which also presents non-decreasing returns. On this respect, Lucas says

Yet as in the preceding discussion, if we simply incorporate diminishing returns into [(2.7)], human capital will lose its status as an engine of growth (and hence its interest for the present discussion). What I want $[(2.7)]$ to 'stand for', then, is an environment in which new goods are continually being introduced, with diminishing returns on learning on them separately [...] In other words, one would like to 
consider the inheritance of human capital within 'families' of goods as well as within families of people. (op. cit. p.28)

Lucas analyzes the implications of these models for international trade and interregional economics, and concludes:

The mcdel that I think is central was developed in section 4. [Human capital] It is a system with a given rate of population growth but which is acted on by no other outside or ixogenous forces. There are two kinds of capital, or state variables, in the system: physical capital that is accumulated and utilized in production under a familiar neoclassical technology, and human capital that enhances the productivity [of] both labor and physical capital, and that is accumulated according ta a 'law' having the crucial property that a constant level of effort produces a constant growth rate of the stock, independent of the level already attained. ( $i b$. p. 39)

A cohclusion from Lucas which is of special value for the present dissertation is stated in page 41:

\footnotetext{
A successful theory of economic development clearly needs, in the first place, mechanics that are consistent with sustained growth and with sustained diversity in income levels. This was the objective of section 4 [Human capital model]. But there is no one patiern of growth to which all economies conform, so a useful theory needs also to capture some forces for change in these patterns, and a mechanics that permits these forces to operate.
} 
The other approach is based on technology as the good that provides the increasing returns to production. As Romer says

The creation of new knowledge by one firm is assumed to have a positive external effect on the production possibilities of other firms because knowledge cannot be perfectly patented or kept secret. iRomer, 1986, p. 10031

Nevertheless, the development of this new knowledge exhibits diminishing returns,

That is, given the stock of knowledge at a point in time, doubling the inputs into research will not double the amount of new knowledge produced. (idem)

Although this is the original version of endogenous growth, it was best presented later by Romer $\$ 1990 \mathrm{a}$, 1990b) who focused on two attributes of goods: rivalry and excludability:

A purely rival good has the property that its use by one firm or person precludes its use by another [...] A good is excludable if the owner can prevent others from using it. (Romer, 1990b, p. S74)

If a good is non-rival, it can be used in more than one process at a time. Knowledge or technology are of this kind. A particular design, once found, can be used in 
several production processes at the same time, providing the increasing returns to production that we have mentioned. Nevertheless, these goods are not perfectly excludable. Copyright and patents are attempts to preclude use by other agents, but they are imperfect, leading to less incentive to produce it.

The original, simpler, model of Romer runs as follows: in a discrete-time setting, individuals select over two goods that are produced using knowledge $(k)$ and a vector $x$ of other variables (labor, physical capital, etc.). He assumes that knowledge is produced from foregone consumption.

Since newly produced private knowledge can be only partially kept secret and cannot be patented, we can represent the technology of firm $i$ in terms of a twice continuously differentiable production function $F$ that depends on the firm-specific inputs $k_{i}$ and $x_{i}$ and on the aggregate level of knowledge in the economy $(K)$. (Romer, 1986, p.1015)

$F$ is assumed to be concave and homogenous of degree one in $k_{i}$ and $x_{i}$. From these assumptions and the increasing returns to the aggregate level of knowledge, $F$ exhibits increasing returns to scale. The equilibrium is competitive, with externalities: 
Each firm maximizes profits taking $k$, the level of knowledge, as given. Consumers supply part of their endowment of output goods and all the other factors $x$ to firms in period 1. With the proceeds, they purchase goods in period 2. Consumers and firms maximize taking prices as given. (op. cit., p. 1016)

In this setting, fixed point solutions can be found. Romer goes on to an infinite-horizon model, similar to the one just presented, and states two theorems of particular importance. Theorem 1..(op.cit.p.1021) shows that if the utility function and the percentage physical capital growth function are concave, and if there is an upper bound to physical capital grow, then there exists a finite-valued solution to a planning program that maximizes utility, provided that the transversality condition is fulfilled.

The second theorem (op.cit., p.1024) extends the result to show that, assuming additionally that the functions are twice continuously differentiable ${ }^{3}$, there exists a competitive equilibrium with externalities. He refers to his dissertation for the proof. Romer concludes this paper (1986) stressing some lines of research, although recognizing the complexity of the analysis.

There are other technical assumptions not relevant for the exposition. 
After these seminal papers, a lot of work has been spent in developing what is now known as the new growth tieory. The increasing returns that endogenize technical progress...have been identified with human capital, as we have seen in Lucas, but also with development of new products or quality increases (Stokey, 1988; Grossman and Helpman, 1991, develop an excellent book starting from this approach; also Rustichini and Schmitz, 1991, and Segerstrom, 1991). Advances in the study of growth in relation to international trade can be found in RiveraBátiz and Romer (1991). Many studies also analyze the effect of knowledge accumulation on growth, among them Adams (1990), Chari and Hopenhayn (1991), Ehrlich and Lui (1991) and Fung and Ishikawa (1992). Since this field is very new, some technical problems in the models are being solved (Tamura, 1991; Yang and Borland, 1991; Zilcha, 1992).

Another important point that is being incorporated in the endogenous growth models is the role of government. The most important references in this respect are King and Rebello (1990) and Rebello (1991). For the role of government on the creation of human capital and the indirect effect in growth, see Young and Kim (1992) and Halperin and Teubal(1991). 
The empirical relation between human capital and growth had been recognized before. Kim (1976; cited by jung, 1992) estimated the contribution of education to output growth in Korea during the period 1960-1974 to be about $8 \frac{3}{3}$ of the total. Nevertheless, the new theoretical framework allows us to explore the relation in greater depth. Barro (1991), in his cross-country study of growth, found significant relationship among growth rates and secondary education, where this variable is a proxy for human capital. Nevertheless, he also found that certain southeast Asian countries grew faster than what human capital theory would predict, while entire continents (Africa and Latin America) grew more slowly ${ }^{4}$ A very interesting paper by Grossman (1989) analyzes the differences in growth rates between Japan and the U.S.A. with respect to human capital, finding support for the hypothesis of endogeneity. Other studies by Barro (1989, 1990; with Sala-i-Martin, 1990) focus on the effect of government spending on growth, in the light of endogeneity.

This result was the motivation for the model developed in this dissertation. 
Nevertheless, the empiricai battle has just begun. Mankiw, Romer and Weil (1992) used an augmented-solow model where both human and physical capital are accumulated and found evidence that supports the convergence hypothesis5, while Barro (1991) found evidence to the sntrary.

The convergence hypothesis is a standard result of exogenous growth theory which states that all countries will tend to have a similar growth rate as they grow.

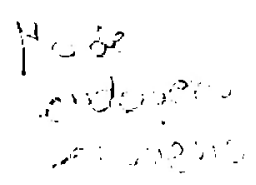


CHAPTER 2

INCOME DISTRIBUTION

Income distribution is a very polemical issue. It doesn't seem to be such a good idea that certain people should have less income than others, while it would probably seem worse that everybody had the same. Leaving ethical issues aside, although sen (1992) wouldn't agree, income distribution may induce a significant distortion in resource allocation. Although the next chapter deals with the relation between demographic factors and income, it can be stated here that the distribution of income is less egalitarian than any other demographic variable (Atkinson, 1975).

I. Income Distribution Measurement ${ }^{1}$..

Poverty distorts resource allocation since poor people don't have the opportunity to participate in production with the same efficiency as the rest. Nevertheless, income

For this section, any textbook on inequality may be useful. In particular, Atkinsan (1975). Garcia Rocha (1986), Cortés and Rubalcava (1984), Jung (1990). 
distribution and poverty are not the same thing, and they may not even be correlated. Figure 3.1 presents two diEferent income distributions. L1 is less egalitarian than i2 as measured by the Gini coefficient; however, there is less poverty under L1 than under L2.

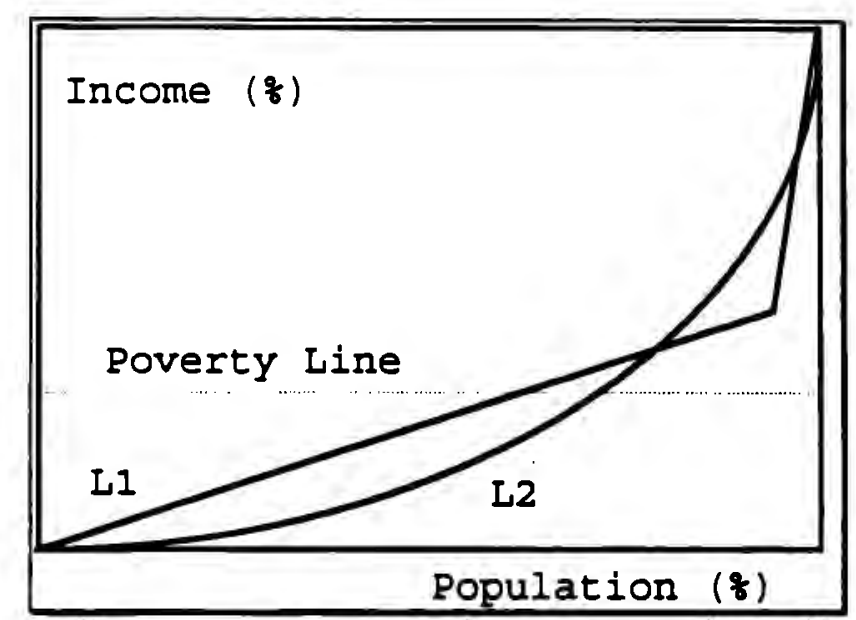

Figure 2.1. Poverty and Income Distribution

The curves L1 and L2 in Figure 3.1 are called "Lorenz curves.". We measure on the horizontal axis the percentage of the population and on the vertical axis the cumulative income received by that percentage (from 0 to 100\%), sorted by their income. The figure and the preceding paragraph illustrate one of the problems with income distribution: its measurement.

The most widely used measure of income inequality is the Gini coefficient: 


$$
G=1-2 \int_{0}^{1} L(z) d z
$$

where $L(z)$ is the Lorenz curve. In terms of Fig. 2.1, the Gini coefficient would be twice the area between a specific Lorenz curve (say LI) and the $45^{\circ}$ line. That is, twice the difference between a certain distribution and a perfectly egalitarian one. There are two problems in constructing this coefficient. First, we normally have only 5 or 10 data points, the income received by quintiles or deciles. For some cases, like the U.S.A., we might have percentile information, but that happens very seldom. The area below the Lorenz curve must then be approximated by rectangles. The second problem is that $L(z)$ doesn't have an analytical form. Some efforts have been made to find a function that fits the Lorenz curve (Basmann, Hayes, Slottje and Johnson, 1990; Basmann, Hayes and Slottje, 1991) but the main problem is still that the "tails" of the distribution are very hard to approximate in a simple model.

Another measure of inequality is Theil's entropy index, which is an application of the shannon index of entropy in communication theory (Shannon and Weaver, 1949). Theil's index is: 


$$
H=\sum_{i=1}^{n} L\left(z_{1}\right) \log \frac{L\left(z_{1}\right)}{z_{1}}
$$

where, if distribution is completely uniform, $H=0$, and if all income is in the hands of a single agent, $H=1 n n$, where $\mathrm{n}$ is the number of agents.

Two other income distribution indices are the variance of income logarithms, defined as

$$
V=n \sum_{i=1}^{n}\left(\log L\left(z_{i}\right)-\log \mu\right)^{2}
$$

where $V$ goes from 0 to infinity as inequality increases. A similar measure is the Coefficient of Variation, defined as

$$
C V=\frac{\sigma}{\mu}
$$

where $\sigma$ is the standard deviation of income distribution and $\mu$ is the mean income. 
Other measures of distribution focus on differences in earnings (such as Atkinson's earnings tree) or in income among ..two population subgroups (like the top $20 \frac{3}{3}$ bottom $401)$. The advantage of these measures is that they are very illustrative of inequalities, although they are not very useful for calculations, which is the strong point of the Gini and Theil's indices.

Inequality measures should have two properties to be useful for analysis: i) the measure shouldn't change with scale changes; and $i i)$ the measure should satisfy the Pigou-Dalton condition ${ }^{2}$. Table 3.1 presents the above inequality measures and the properties each one has.

\begin{tabular}{|c|c|c|c|c|}
\hline Measure & Invariant & WPD & SPD & Range \\
\hline Range & Yes & Yes & No & $0-\propto$ \\
\hline Log Var & Yes & No & No & $0-\propto$ \\
\hline Theil & Yes & Yes & Yes & $0-\infty$ \\
\hline Gini & Yes & Yes & No & $0-1$ \\
\hline
\end{tabular}

Table 2.1. Inequality Measures

NOTE: WPT is the weak Pigou-Dalton condition, SPT the strong condition. Invariant means if changes in scale preserve the inequality measure.

-This condition requires that if a transfer is made from the rich to the poor, the inequality measure must decline. The strong version requires in addition, that if the transfer is made from the rich to a middle-income individual, the measure should differentiate it from the former transfer. 
II. Income Distribution and Demographic Factors

One of the most interesting relationships in development economics is that between demographics and ircome. If we made a cross sectional study of birth rates and income per capita, we could easily see a negative relation. The richer the country, the fewer the births. For example, European countries (Switzerland, France, Netherlands, United Kingdom, etc.) have an income per capita ranging from 6 to 10 thousand dollars and women in those countries normally have less than two children during their lifetime. On the other hand, in Latin American countries (like Mexico, Brazil, Colombia, etc.) with an income per capita below 2,000 dollars, women normally have between 4 and 6 children in their lifetime (Herrick and Kinjleberger, 1983, p.366).

Furthermore, the fewer people that are born in the richer countries tend to live longer. Again from Herrick and Kindleberger(1983, p.365), in very poor countries like Ethiopia, Bangladesh or India (not more than 200 dollars per capita) people have a life expectancy of 40 to 50 years. In middle income countries, like Latin America, this goes up to 60 years. Europe and other developed countries exhibit life expectancies of 70 to 75 years (all 
data are from 1980). Nevertheless, as recently as 1900, these countries exhibited life expectancies not very different from the ones in Asia now. Denmark's was 53 years and Norway's around 54, but the rest had about 40 jears, with Russia and Spain very close to 30 years. Not surprisingly, income per capita was also close to what we cbserve today in Asia. Austria had 400 dollars, Italy 300, United Kingdom 900, etc. (Dasgupta, 388, pp.154-155).

In fact, the decrease in mortality rates in the underdeveloped countries has been faster than the decline in birth rates, leading to the demographic boom of this century (Kuznets, 1983, p.99ff). This indicates that it is possible to live longer without a significant increase in per capita incomes, thanks to modern surgery and drugs, but that it is difficult to change the behavior of the people towards reproduction. The reason could lie well beneath the surface. As an example, poor countries tend to have more people living in rural areas than in cities (Herrick and Kindleberger, 1983, p.389) and in the country more children mean more hands to help in the crops, which seems a good reason not to stop having children ${ }^{3}$.

isee Gary Becker's analysis of birth economics (Becker, 1993). 


\begin{abstract}
Nevertheless, we know empirically that a more egalitarian income distribution also means fewer children. In fact, the relation between income distribution and birth rates is stronger than the relation between income distribution and income per capita. The relation between rural population and income distribution is even stronger (Herrick and Kindleberger, 1983, pp. 137,366,389). Nevertheless, we must not forget that death rates are normally also greater in poorer countries, as Kuznets noted in the case of population groups in the U.S. (Kuznets, 1983, pp.101 ff).
\end{abstract}

The evidence seems to point to what we already noted in the previous chapter: growth without redistribution probably is not a very desirable objective. Development, or an enhanced quality of life, seems to be positively related to both income redistribution and economic growth, at the same time.

The question now should be: Does income distribution depend on demographic factors also? That is, is there a two-way relationship between demographic factors and income distribution? The evidence seems to point to a positive answer. Taubman (1974) finds some effects on income distribution by demographic factors like education, 
mental abilities and non-economic incentives (pp.1-20). Eiso Kuznets (1983, pp.131-239) addresses this issue, but rainly to describe the difficulties associated with measurement. In fact, it seems that micro-demographic factors (like education, abilities, religion) affect income distribution, while income distribution affects macro-demographic factors" (health, poverty, etc.).

When we talk about income distribution, we tend to think that an egalitarian distribution is better than the opposite. This may not be true. As Dasgupta (1988, p.58) says: "equality is not so good. Nobody literate is as equal as everybody literate." And these two points are obviously different in terms of welfare. Thus egalitarian) income distribution with low incomes might be worse than non-egalitarian distribution of higher incomes, as is the case of the Unites States.

A very important point is that institutions may determine most of the inequality. From the papers of Krueger (1990), Krueger and Orsmond (1990), Findlay and Wilson (1987) and Perroti (1992), we can state that microeconomic incentives to maintain inequality may be -present at the political level. Empirical evidence in Tabellini and Persson $(1991)^{\star}$ also lends support to the 
point that different institutions may lead to different income distributions.

III. Income Distribution and Economic Growth

Since Kuznets's (1955) study of economic growth and income distribution and the sequence of "U-curve" articles (for example: Ram, 1991; for a survey on this topic before 1990, see Jung, 1990), it has not been possible to reach an agreement on the most important question: Does the income distribution affect economic growth? In order to find the answer, theoretical models have been developed attempting to capture the way that income distribution may affect growth. Persson and Tabelini (1991) constructed a model where income distribution affects growth through a political mechanism. Moulin and Thomson (1988) answer the converse question, can growth benefit everybody? Their answer is no, there is no possibility, under their assumptions, that everybody would benefit when the country grows.

A final remark should be that the theoretical efforts have tended to focus only on one aspect at a time, while the question is not whether income distribution affects 
growth or viceversa, the question is: what is the relationship between income distribution and economic growth? 
PART II

ECONOMIC GROWTH AND INCOME DISTRIBUTION 


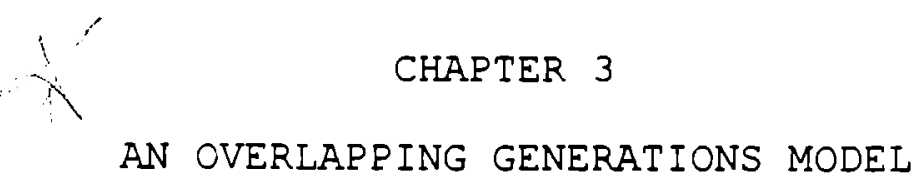

In this chapter, I present a model by Persson and Tabellini that analyzes income distribution along with economic growth. Most of this chapter is taken from their work, although I introduce a modification to their model that appears in section $V$.

I. The Model

Persson and Tabellini (1991) present an overlapping generations model in which income distribution and economic growth are studied simultaneously. In their model, consumers maximize their utility over the goods consumed in the two periods they are allowed to live. Utility is defined as

$$
v_{t}^{i}=U\left(c_{t-1}^{i}, d_{t}^{i}\right)
$$

where $c$ represents consumption in the first period and $d$ in the second. The superscript i denotes the consumer. In 
the first period, consumption competes with capital accumulation,

$$
c_{t-1}^{\prime}+k_{t}^{\prime}=y_{t-1}^{\prime}
$$

$k$ is the capital accumulatid by individual $i$ to be consumed during period 2, where this stock of capital permits period 2 consumption,

$$
d_{t}^{\prime}=r_{t}\left[\left(1-\theta_{t}\right) k_{t}^{\prime}+\theta_{t} k_{t}\right]
$$

where $r$ is the "growth factor" of the country. Redistribution happens in this second period through $\theta$, which is a kind of redistributive tax on the capital stock, since $k_{t}$ is the average stock of capital in the country.

Income in the first period is:

$$
y_{t-1}^{i}=\left(\omega_{t-1}+e_{t-1}^{i}\right) k_{t-1}
$$

where the term in parentheses is drawn from the income distribution, understood here as a stochastic variable $e$ that is distributed with zero mean and a variance dependent on capital stock, $k$. The distribution is 
generally specified as $F\left(e^{\prime}, k\right)$. The median of this distribution is assumed to be less than one. $\omega$ is an exogenously determined endowment of "basic abilities" specific to the country.

The program is that at the beginning of period $t-1$, voters elect $\theta_{t}$. After that, investors select $\boldsymbol{k}_{t-1}$. A political-economic equilibrium is defined as a policy and a set of private economic decisions such that: 1) economic decisions are optimal, for a given redistributive policy, and markets clear; 2) The policy can not be defeated by any alternative in a majority election amongst the citizens.

\section{Economic Equilibrium}

With homothetic preferences, the intertemporal decision depends only on prices, that is, on the "interest rate". Then we can define $d_{t} / c_{t}=D\left(r_{t}, \theta_{t}\right)^{1}$, where $D_{r}^{\prime}>0$ and $D_{\theta}^{\prime}<0$. Given this, we can find the consumed amounts of each good,

:I will omit the subindices in the function $D$ for clarity. 


$$
c_{t-1}^{\prime}=r_{t} \frac{\left[\left(1-\theta_{t}\right) y_{t-1}^{\prime}+\theta_{t} k_{t}\right]}{\left(1-\theta_{t}\right) r_{t}+D(r, \theta)}
$$

and

$$
d_{t}^{\prime}=c_{t-1}^{\prime} D(r, \theta)
$$

For the average consumer, $k_{t}=y_{t-1}-c_{t-1}$. We can define the average rate of growth as $g=k_{t} / k_{t-1}-1$, that is,

$$
g=\frac{\omega_{t-1} D(r, \theta)}{r_{t}+D(r, \theta)}-1
$$

with

$$
\boldsymbol{g}_{\omega}^{\prime}>0, \quad \boldsymbol{g}_{\theta}^{\prime}<0, \quad \boldsymbol{g}_{r}^{\prime}{ }_{<}
$$

This model is recursive, given an initial condition $k$ and a sequence $\left\{\theta_{1}, \omega_{1}, r_{1}\right\}$ we can find a growth rate sequence.

\section{Political Equilibrium}

Given the utility functional form, we can rewrite it like $U\left(c_{t-1}, d_{t}\right)=c_{t-1} U(1, D(r, \theta))$, and consequently,

$$
v_{t}^{i}=V(r, \theta)\left[W(\omega, r, \theta)+e_{t-1}^{i}\right] k_{t-1}
$$


where

$$
V(r, \theta)=\left[1+\frac{D(r, \theta)}{r(1-\theta)}\right]^{-1} U(1, D(r, \theta))
$$

with

$$
V_{\theta}<0, \quad V_{r}^{>} 0
$$

and

$$
W(\omega, r, \theta)=\omega_{\imath}\left[1+\frac{\theta_{t} D(r, \theta)}{\left(1-\theta_{t}\right)\left(r_{t}+D(r, \theta)\right)}\right]
$$

with

$$
W_{\theta}>0, \quad W_{\omega}=W / \omega>0, \quad W_{\theta \omega}=W_{\theta} / \omega>0
$$

Since preferences are linear over e, they belong to the class on intermediate preferences studied by Grandmont (1978). Given that $v$ has a unique maximum in $\theta$, we have a median-voter result: The equilibrium policy is the $\theta$ preferred by the median voter. Let $\boldsymbol{e}_{\boldsymbol{m}}$ be this voter, then the equilibrium policy $\theta_{i}$ is implicitly defined by

$$
V_{\theta}\left(W+e_{t-1}^{m}\right)+V W_{\theta}=0
$$


which reflects the trade-off that voters face. On the one hand, an increase in $\theta$ redistributes income; on the other, it diminishes investment and, therefore, decreases the base for redistribution: general income.

IV. Dynamics of Growth

From the model stated before, very different growth patterns can be drawn. Depending on the initial condition of $k$ and the form of $F\left(e^{i}, k\right)$. Some of these patterns are non-monotonic, giving some theoretical support for the Kuznets' U curve, ...or also an inverted $U$. To support their model, Persson and Tabellini present an empirical analysis of different countries with diverse political and economic characteristics. Finally, they pose some ways to enrich the model, among them, richer savings behavior and discrimination about the mechanism through which distribution affects growth. Persson and Tabellini conclude:

The main theoretical result is that income inequality is harmful for growth, because it leads to policies that do not protect property rights and do not allow full private appropriation of returns to investment. (Persson and Tabellini, 1991, p.30) 
and state that historical evidence supports this. This conclusion arises from the fact that if an individual saves...in period $t-1$ in order to have more consumption in tr-and the rest of the agents don't save, the political equilibrium will tend to impose a tax on the savings of the agent that saved, making savings less attractive. Eollowing this argument, there are fewer incentives to accumulate capital than in the case when the redistributive tax doesn't exist, and since growth is stated in terms of the capital stock, it will be lower. Thus, inequality is harmful for growth in this model because of this indirect effect through political equilibrium and the reduction of incentives to accumulate capital.

V. Minimal Consumption

Following one of the lines of research proposed by the authors, I consider a diferent saving behavior in the model through the constraint of a minimal consumption. If there is not enough income for individuals to survive, redistribution must have different patterns. We are assuming that there is a minimal consumption requirement 
denoted by $C_{\text {min }}$. This can be thought of as the minimal consumption of goods that allows the country not to suffer a revolt.

Under this restriction, for certain levels of $k_{t-1}$ the country doesn't have political feasibility, since given a certain distribution, the income will not be enough to consume in period one, leaving savings aside. This doesn't have anything to do with redistributive policy, since we are talking about consumption in period one. Nevertheless, when we are not in this extreme case, redistributive policies will have a floor.

Let us take this case: When income in the first period is enough to consume and save, then it is possible to have a second period, but we are not sure that savings from the first period will be enough to ensure that $C_{\min }$ will be attained by all agents in the second period. Following this argument, we find the minimal $\theta$ that guarantees political stability:

$$
d_{t}^{i}=r_{t}\left[\left(1-\theta_{t}\right) k_{t}^{i}+\theta_{t} k_{t}\right] \geq d_{\min }=c_{\min }
$$

and, solving for $\theta_{\min }$ 


$$
\theta_{\min } \geq 1 / r_{t}\left[\frac{c_{\min }\left(1+r_{t}\right)-\left(\omega_{t-1}+e_{t-1}^{p}\right) r_{t} k_{t-1}}{k_{t}-\left(\omega_{t-1}+e_{t-1}^{p}\right) k_{t-1}}\right]
$$

where $e_{t-1}^{p}$ is the ability endowment of the individuals that $k_{t-1}$ we have
are below the poverty line. Differentiating (/.13) against

$$
\frac{\partial \theta_{\min }}{\partial k_{t-1}}=\frac{\omega_{t-1}+e_{t-1}^{p}}{r_{t}\left[k_{t}-\left(\omega_{t-1}+e_{t-1}^{p}\right) k_{t-1}\right]^{2}}\left[k_{t} r_{t}-c_{\min }\left(1+r_{t}\right)\right]
$$

which is non-positive. These two equations are represented graphically in Eigure 3.1, where we can see the redistributive floor mentioned before.

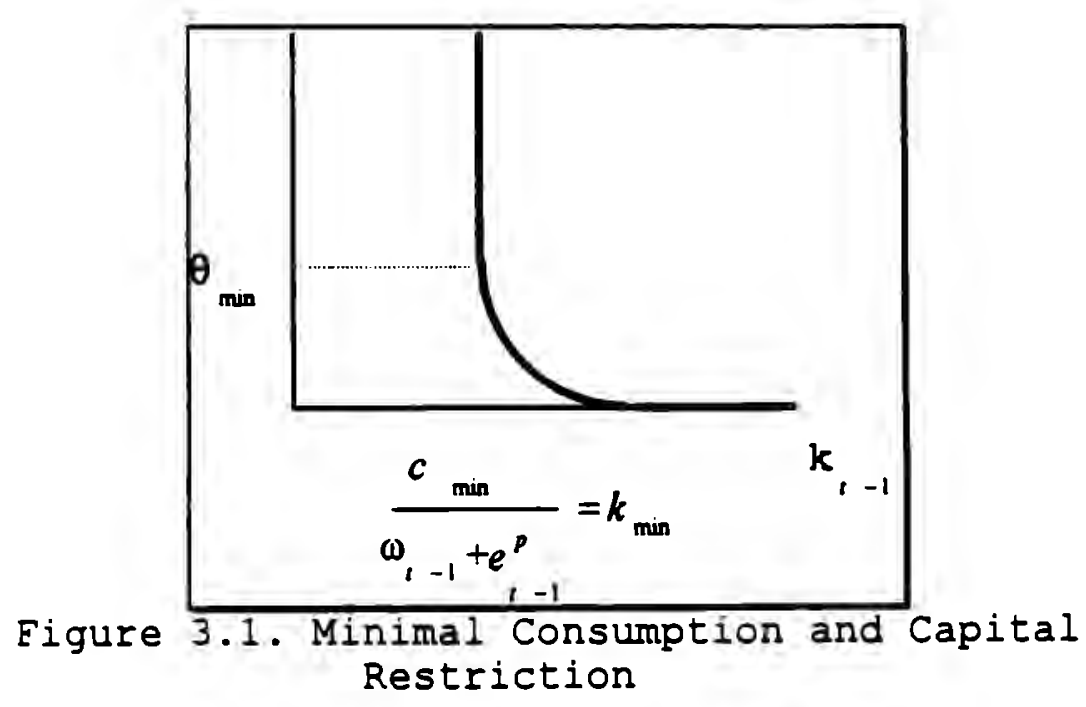


The conclusions are quite interesting, if the country is below (or to the left of) the solid line in 3.1 , a political struggle can be predicted. Nevertheless, it can be better understood if we look at it from the poverty fraction of the country. We have defined a poverty line, and if too many citizens are below it, $\theta_{\mathrm{min}}$ grows up to $100 \frac{2}{3}$. Differentiate (3.13) against $p$ to find

$$
\frac{\partial \theta_{\min }}{\partial p}=\frac{r_{t} k_{t}-c_{\min }}{(1-p)^{2}}
$$

which tends asymptotically to infinity as $p$ tends to one. Eigure 3.2 presents this case.

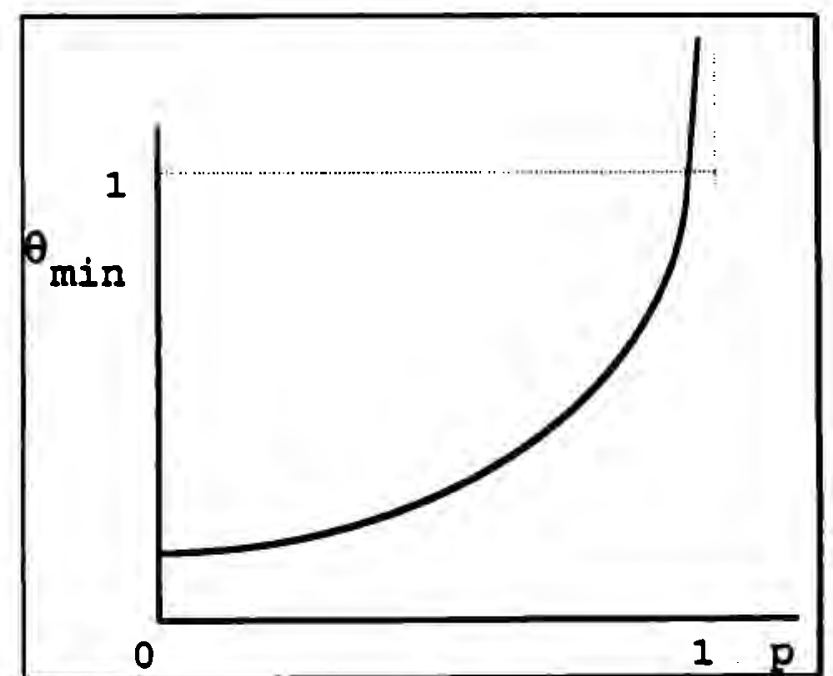

Figure 3.2. Amount of Poverty and minimal redistribution tax 
Now, what happens with growth? As in the original model, the greater the need for redistribution, the slower the rate of growth. Then, from 3.15 the greater the amount of poor people, the slower the countey will grow. If there is a poverty trap; anywhere, this is it.

Under this modification to the model of Persson and Tabelini, their conclusions become stronger. If inequality was harmful for growth in the original-model, because of political equilibrium, under the new-assumption inequality might even lead to political-unfeasibility for a country. For certain levels of capital in the starting period, the country doesn't even have a chance to apply redistributive efforts. At first glance, some countries may actually be suffering this disease. Note that this result depends on the assumptions on the voting capability of poor people. If they are not allowed to vote, then the minimal redistributive tax would be very different. In fact, Persson and Tabellini also find that if vote is restricted to the rich people, the country will grow faster since no redistributive $\operatorname{tax}$ (or at least not very big) will be imposed on the capital stock, avoiding the reduction of incentives to save. Nevertheless, our argument still holds since even if poor people are not 
allowed to vote, if the redistributive tax is not enough to permit everyone fulfill basic needs (that is what $C_{\text {mun }}$ is about) then the political feasibility of the country becomes endangered since the cost of continuing under the political system becomes excessive for the poor and the cost of joining a revolt becomes relatively smaller. This argument may explain the successive political reforms in underdeveloped countries that are normally condemned by rich people, since those reforms lead to tax and subsidy increments while the government defends them by stating that the stability of the country is more important than economic growth in those circumstances. Also this argument may be effective in dealing with the issue that some countries do not reach political stability if not ruled by dictators, being at the same time very poor countries. The poor-unstable duality that, for example, Latin American or African countries suffer may be, in fact, a vieious circle resting on a faulty combination of capital-stock and redistributive efforts. 
CHAPTER 4

APPROXIMATING THE LORENZ CURVE

\begin{abstract}
Approximating the Lorenz curve has been a major issue in empirical work on income distribution. Since Pareto (1897), a considerable amount of effort has been spent in finding a function that approximates this curve (for example, Aitchinson and Brown, 1957; Champernowne, 1953). In particular Basmann, Hayes, Slottje and Johnson (1990) and Basmann, Hayes and Slottje (1991) present a function that approximates the Lorenz curve which can also be interpreted in terms of the difficulty of moving up the income distribution. In this chapter a different function is presented that makes a somewhat better approximation to the curve.
\end{abstract}

I. The Function

An: interesting approach to the Lorenz curve is the use of the mobility function. Basmann et al. (1990, 1991) define the mobility function as the perceived difficulty of moving up in the income distribution. This perceived difficulty is assumed to be a function of the agent's 
current position. The steeper the Lorenz curve around the actual position of the agent, the greater the difficulty. The Lorenz curve is

$$
L(z)=A z^{\alpha}(\gamma-z)^{\beta}
$$

where $\alpha>1, \quad \beta<0$ and $\gamma>1$. The parameter $A$ is really a function of $\gamma$ and $\beta$, since $L(1)$ must be 1 . Then

$$
A=(\gamma-1)^{-\beta}
$$

substituting, we have

$$
L(z)=z^{\alpha}\left(\frac{\gamma-z}{\gamma-1}\right)^{\beta}
$$

dependent only on three parameters. This function (which will be called the "gamma function" hereafter) has the following derivative with respect to $z$ :

$$
\frac{\partial \mathrm{L}(\mathrm{z})}{\partial \mathrm{z}}=I(z)=L(z)\left[\frac{\alpha}{z}-\frac{\beta}{\gamma-z}\right]
$$

I (z) is defined as the mobility function. It can be understood as the perceived difficulty for individuals to move... up in the distribution. This function is. monotonically increasing, meaning that the closer one 
individual is to the top of the distribution, the more difficult it will be to move further up. Note that in the case of a completely egalitarian distribution, this mobility function would be a constant, that is to say, if everybody has the same earnings, there is no difficulty inchanging position. As $z$ approaches zero, $L(z)$ also approaches zero, making $I(z)$ a very small quantity. When $z$ approaches $1, L(z)$ does the same and $I(z)$ approaches insinity.

The interesting theoretical properties come from the intuition behind the parameters. $\alpha$ is the major determinant of the shape of the lower portion of $z$ las $z \rightarrow$ $0)$, while $\beta$ and $\gamma$ are more influential in the upper part of the curve, that is, when $z \rightarrow 1$. The derivative of $L(z)$ with respect to $\boldsymbol{\alpha}$ is

$$
\frac{\partial L(z)}{\partial \alpha}=L(z) \ln (z) \leq 0
$$

which means that an increase in $\alpha$ will reduce the income received by all the agents since (4.5) is non-positive, but with a greater impact (in absolute terms) on the middle part of the distribution. Nevertheless, the relative effect of a change in $\alpha$ will be more important in 
the lower part of the curve, declining around $z>0.3 . \beta$ and $y$ are the major determinants of the upper portion of the distribution. The derivatives with respect to $\beta$ and $\gamma$ are

$$
\begin{aligned}
& \frac{\partial L(z)}{\partial \beta}=L(z) \ln \left(\frac{\gamma-z}{\gamma-1}\right) \geq 0 \\
& \frac{\partial L(z)}{\partial \gamma}=L(z)\left(\frac{\beta}{\gamma-z}\right)\left(\frac{z-1}{\gamma-1}\right) \geq 0
\end{aligned}
$$

which are always non-negative and monotonically increasing. An increase in $\beta(\beta \rightarrow 0$, since $\beta$ is always less than or equal to 0$)$ will increase the income received by all agents except for $z=1$, that is, income distribution becomes more egalitarian. In fact, when $\alpha=1$ and $\beta=0$, income distribution is uniform. An increase in $\gamma$ produces the same result: A more egalitarian distribution of income.

\section{Empirical Results}

The function $L(z)$ is non-linear. A very important challenge for empirical analysis of income distribution data is that we normally have only five, or at most ten, data points to estimate the function. It is very difficult 
to have initialization values good enough to get meaningful non-linear regression results using only ten daca points. An interesting empirical property of the Function $L(z)$ is that using $\gamma=1$ and then estimating a linearized version of $L(z)$, gives us these initialization ralues. We can apply an iterative method using linear regressions to obtain the non-Iinear parameters, using an algorithm like

1. Set $\gamma=1$.

2. Run linear regression to estimate

$$
\ln L(z)=\ln A+\alpha \ln z+\beta \ln (\gamma-z) \text {. }
$$

3. Set $\gamma_{n}=\exp (1 / \beta \ln (1 / A))+1$

4. If $\left|\gamma_{v}-\gamma\right|>\varepsilon$ then $\gamma=\gamma_{n}$, go to 2 , else finish.

This algorithm makes use of the fact that $L(1)=1$. At this point, if we solve for $\gamma$, we obtain the equation used in step 3. Introducing the new value of $\gamma$ into the function in step 2 leads us to another value of $A$. Since the derivative of $L(z)$ against $\gamma$ (eq. 4.7) is a wellbehaved function, also monotonically increasing, convergence is rapid, and it is generally useful to start with a low value of $\gamma$, like 1 . 
In fact, $\alpha$ and $\beta$ are very stable parameters. Linear regressions for a sample of thirty countries find that $\alpha$ is normally between 1.5 and 1.8 , while $\beta$ lies in the interval $[-0.1,-0.2]$. Using these initialization values, we obtain very good non-linear regression results. It is not clear what $r$. aber of data points is the minimum to obtain good results in the regression, but ten points have worked well.

Using this function to estimate income distribution data gives us results that are comparable to those obtained by Basmann et al. (1990, 1991). Figure 4.1 presents the results using the gamma function with the data provided by Basmann et al. along with the results of Basmann and the actual values of the Lorenz curve using U.S. income distribution data for 1977. As can be clearly seen, the estimated gamma function lies closer to the real values. Figs. 4.2, 4.3 and 4.4 present different sections of the distribution in order to identify the critical regions. It is evident that the gamma function works better than the model of Basmann et al. except for the lowest portion of the distribution. In fact, figures. 4.5 and 4.6 present the residuals of both functions. In absolute terms, the gamma function is always better than the Basmann et al. function. Nevertheless, in relative 
terms, the gamma function is worse in the first quintile, and better from there on.

Table 4.1 presents the results for these one hundred data points. The first two columns contain both estimates, the middle columns present the absolute residuals, and the last two columns the relative residuals. Table 4.2 presents the sum of squares for both estimations, in absolute and relative terms. The gamma function is clearly better in absolute terms, but the residuals in the first decile make it worse in relative terms.

This big difference in the case of the relative residuals may be related to the numerical procedures. In fact, using the algorithm presented above, parameters are somewhat different. Table 4.2 also presents these results. Not surprisingly, absolute errors are bigger in the linear regressions but relative errors are smaller. Fig. 4.7 presents a graphical comparison of the two procedures for estimating gamma, along with the estimates using the Basmann et al. model. Table 4.3 presents the non-linear regression results while Table 4.4 presents the (final) linear estimation results. An interesting additional point for the linear estimation is that the iterative linear 
tecinique allows us to successfully estimate the Lorenz curve using only five data points.

A final point could be made here. Estimations seem to be very consistent. Several tests were performed with the data shown in table 4.1 selecting randomly 4,6 or 8 observations and estimating the parameters. Results of these tests are in table 4.5 and we can see that standard deviations of the parameters are quite small. Maybe the parameter that suffers most from small samples is $\beta$.

\section{Cross-Country and Time-Series}

Using data from the World Bank (1984), we have estimated the gamma function parameters for 28 countries. The data appear in table 4.6 , and the results in table 4.7. This exercise gives us a good idea of the values of the parameters for a wide range of different cultures and institutions. This will be of great help in the next chapters.

A time-series exercise was also made using data from Mexico (IMSS-COPLAMAR, 1981; INEGI, 1988; INEGI, 1992), presented in table 4.8 . The results (Table 4.9 ) seem quite 
consistent with the cross-country case. They will also be used in the next chapter.

\begin{tabular}{|c|c|c|c|c|c|c|c|}
\hline & & \multicolumn{2}{|c|}{ Estimation } & \multicolumn{4}{|c|}{ Residuals } \\
\hline$z$ & $E(z)$ & Basmann & Gamma & asmann & Gamma & Basmann & Gamma \\
\hline .01 & 0.0004 & 0.0004 & 0.0004 & 0.0000 & 0.0000 & $0.00 \div$ & -8.04 \\
\hline 0.02 & 0.0014 & 0.0013 & 0.0011 & -0.0001 & -0.0003 & $-7.14=$ & -18.05 \\
\hline 0.03 & 0.0027 & 0.0026 & 0.0022 & -0.0001 & -0.0005 & $-3.70 ;$ & -17.30 \\
\hline 0.04 & 0.0043 & 0.0041 & 0.0036 & -0.0002 & -0.0007 & -4.65 & $-16.68 !$ \\
\hline 0.05 & 0.0061 & 0.0059 & 0.0052 & -0.0002 & -0.0009 & -3.28 & -15.213 \\
\hline 0.06 & 0.0081 & 0.0080 & 0.0070 & -0.0001 & -0.0011 & -1.233 & -13 \\
\hline 0.07 & 0.0103 & 0.0102 & 0.0090 & -0.0001 & -0.0013 & -0.97 & $-12.60 \vdots$ \\
\hline 0.08 & 0.0127 & 0.0126 & 0.0112 & -0.0001 & -0.0015 & -0.79 क & -11.653 \\
\hline 0.09 & 0.0153 & 0.0152 & 0.0136 & -0.0001 & -0.0017 & $-0.65 z$ & -10.938 \\
\hline 0.10 & .0180 & 0.0180 & 0.0162 & 0.0000 & -0.0018 & 0.008 & -9.898 \\
\hline 0.11 & 0.0208 & 0.0210 & 0.0190 & 0.0002 & -0.0018 & 0.968 & -8.718 \\
\hline 0.12 & 0.0238 & 0.0241 & 0.0219 & 0.0003 & -0.0019 & $1.26 \%$ & -7.867 \\
\hline 0.13 & 0.0270 & 0.0273 & 0.0250 & 0.0003 & -0.0020 & 1.113 & -7.263 \\
\hline 0.14 & 0.0302 & 0.0 & 0.0283 & 0.0005 & -0.0019 & $1.66 \%$ & -6.248 \\
\hline 0.15 & 0.0337 & .0342 & 0.0318 & 0.0005 & -0.0019 & 1.488 & -5.788 \\
\hline 0.16 & 0.0372 & 0.0379 & 0.0353 & 0.0007 & -0.0019 & 1.888 & -4.983 \\
\hline 0.17 & 0.0409 & 0.0416 & 0.0391 & 0.0007 & -0.0018 & 1.718 & $-4.41 \%$ \\
\hline 0.18 & 0.0447 & 5 & 0.0430 & 0. & -0.0017 & 1.793 & -3.802 \\
\hline 0.19 & 0.0487 & $3 E_{1}$ & 0.0471 & 0. & -0.0016 & 1.857 & $-3.37 z$ \\
\hline 0.20 & 0.0528 & 0.0537 & 0.0513 & 0.0009 & -0.0015 & 1.703 & -2.913 \\
\hline 0.21 & 0.0570 & 0.0580 & 0.0556 & 0.0010 & -0.0014 & 1.753 & $-2.42 \mathrm{z}$ \\
\hline 0.22 & 0.0614 & 24 & 0.0601 & 0.0010 & -0.0013 & 1.63 영 & -2.09 3 \\
\hline 0.23 & 0.0659 & 0 & 0.0648 & 011 & -0.1 & $1.67 \%$ & -1.728 \\
\hline 0.24 & 0.0706 & .0716 & 0.0696 & 010 & -0.0010 & 1.42 영 & -1.483 \\
\hline 0.25 & 0.0754 & 0.0764 & 0.0745 & 0.0010 & -0.0009 & 1.338 & $-1.21 \%$ \\
\hline 0.26 & 0.0804 & .0813 & 0.0796 & 0.0009 & -0.0008 & $1.12 \mathrm{z}$ & -1.048 \\
\hline 0.27 & .0854 & 3 & 0.0848 & 9 & -0.0 & 1.053 & -0.723 \\
\hline 0.28 & 0.0906 & {$[4$} & 0.0901 & 008 & -0.0005 & 0.888 & -0.509 \\
\hline 0.29 & 0.0960 & 0.0967 & 0.0956 & 0.0007 & -0.0004 & 0.738 & -0.373 \\
\hline 0.30 & 0.1015 & 0.1021 & 0.1013 & 0.0006 & -0.0002 & 0.598 & -0.218 \\
\hline 0.31 & 1071 & 6 & 0.1071 & & 0.1 & 0.478 & $-0.04 \%$ \\
\hline 0.32 & 0.1129 & 0.1132 & 0.1130 & 0.0003 & 0. & 0.279 & 0.078 \\
\hline 0.33 & 0.1189 & 0.1190 & 0.1190 & 0.0001 & 0.0001 & 0.088 & 0.128 \\
\hline 0.34 & 0.1249 & 0.1249 & 0.1252 & 0.0000 & 0.0003 & 0.008 & 0.273 \\
\hline 0.35 & 0.1311 & 0.1309 & 0.1316 & -0.0002 & 0.0005 & -0.153 & 0.363 \\
\hline 0.36 & 0.1375 & 0.1371 & 0.1380 & -0.0004 & 0.0005 & -0.298 & 0.408 \\
\hline 0.37 & 0.1440 & 0.1434 & 0.1447 & & 0.0007 & -0.428 & 0.46 \\
\hline .38 & 1506 & 0.1498 & 0.1514 & -0.0008 & 0.0008 & -0.538 & 0.545 \\
\hline 0.39 & 0.1574 & 0.1564 & 0.1583 & -0.0010 & 0.0009 & -0.648 & 0.583 \\
\hline 0.40 & 0.1644 & 0.1631 & 0.1653 & -0.0013 & 0.0009 & -0.798 & 0.57 \\
\hline
\end{tabular}

Table 4.1. Estimation Results and Comparison with Basmann et al. 


\begin{tabular}{|c|c|c|c|c|c|c|c|}
\hline & & \multicolumn{2}{|c|}{ Estimation } & \multicolumn{4}{|c|}{ Residuals } \\
\hline$z$ & $I(z)$ & Basmann & Gamma & $\operatorname{mann}$ & Gamma & Basmann & Gamra \\
\hline 0.11 & 0.1716 & 0.1699 & 0.1725 & -0.0017 & 0.0009 & $-0.99 \div$ & 0.53 \\
\hline 0.42 & 0.1788 & 0.1769 & 0.1798 & -0.0019 & 0.0010 & -1.06 & $0.58 \%$ \\
\hline 2.43 & 0.1962 & 0.1841 & 0.1873 & -0.0021 & 0.0011 & $-1.13 \vdots$ & 0.58 \\
\hline 0.44 & 0.1937 & 0.1914 & 0.1949 & -0.0023 & 0.0012 & -1.198 & 0.61 \\
\hline 0.45 & 0.2014 & 0.1988 & 0.2026 & -0.0026 & 0.0012 & -1.293 & 0.619 \\
\hline 0.45 & 0.2093 & 0.2064 & 0.2105 & -0.0029 & 0.0012 & -1.39 & 0.58 \\
\hline 0.47 & $0.2: 73$ & 0.2142 & 0.2185 & -0.0031 & 0.0012 & $-1.43 \vdots$ & $0.57 \%$ \\
\hline 0.48 & 0.2255 & 0.2221 & 0.2267 & -0.0034 & 0.0012 & -1.513 & $0.54 \div$ \\
\hline 0.49 & 0.2339 & 0.2302 & 0.2350 & -0.0037 & 0.0011 & -1.58. & 0.49 \\
\hline 0.50 & 0.2424 & 0.2385 & 0.2435 & -0.0039 & 0.0011 & $-1.61 \div$ & 0.463 \\
\hline 0.51 & 0.2511 & 0.2470 & 0.2521 & -0.0041 & 0.0010 & $-1.63 \%$ & 0.42 \\
\hline 0.52 & 0.2599 & 0.2556 & 0.2609 & -0.0043 & 0.0010 & -1.65 列 & 0.393 \\
\hline 0.53 & 0.2689 & 0.2644 & 0.2699 & -0.0045 & 0.0010 & -1.67 年 & 0.353 \\
\hline 0.54 & 0.2780 & 0.2734 & 0.2789 & -0.0046 & 0.0009 & $-1.65 z$ & 0.343 \\
\hline 0.55 & 0.2873 & 0.2826 & 0.2882 & 447 & 0. & -1.64 왁 & 0.313 \\
\hline 0.56 & 0.2968 & 0.2920 & 0.2976 & 048 & 0.0008 & -1.62 का & 0.268 \\
\hline 0.57 & 0.3064 & 0.3016 & 0.3071 & -0.0048 & 0.0007 & -1.573 & 0.248 \\
\hline 0.58 & 0.3162 & 0.3114 & 0.3169 & 048 & 0.0007 & $-1.52 \frac{3}{3}$ & 0.218 \\
\hline 0.59 & 0.3262 & 0.3215 & 0.3268 & 47 & 0. & -1.44 z & 0.178 \\
\hline 0.60 & 0.3364 & 0.3317 & 0.3368 & -0.0047 & 0.0004 & -1.408 & 0.128 \\
\hline 0.61 & 0.3467 & 0.3421 & 0.3471 & -0.0046 & 0.0004 & $-1.33=$ & 0.108 \\
\hline 0.62 & 0.3572 & 0.3528 & 0.3575 & -0.0044 & 0.0003 & -1.23 하 & $0.07 \frac{3}{3}$ \\
\hline 0.63 & 0.3679 & 0.3637 & 0.3680 & 42 & 0. & -1.143 & 0.043 \\
\hline 0.64 & 0.3787 & 0.3749 & 0.3788 & -0 & 0.0 & -1.008 & $0.03 \%$ \\
\hline 0.65 & 0.3898 & 0.3863 & 0.3898 & -0.0035 & 0.0000 & -0.908 & -0.018 \\
\hline 0.66 & 0.4010 & 0.3979 & 0.4009 & -0.0031 & -0.0001 & -0.778 & $-0.02 \frac{8}{3}$ \\
\hline 0.67 & 0.4125 & 0.4098 & 0.4122 & 27 & -0 . & -0.658 & $-0.06 ?$ \\
\hline 0.68 & 0.4241 & 0.4 & 0.4238 & 21 & -0 . & -0.508 & -0.083 \\
\hline 0.69 & 0.4360 & 0.4344 & 0.4355 & 16 & -0 & -0.37 क & -0.113 \\
\hline 0.70 & 0.4481 & 0.4471 & 0.4475 & -0.0010 & -0.0006 & $-0.22 \%$ & -0.148 \\
\hline 0.71 & 0.4603 & 0.4601 & 0.4596 & -0.0002 & -0. & -0.048 & $-0.14 \frac{2}{3}$ \\
\hline 0.72 & 0.4728 & 0.4 & 0.4720 & 36 & -0 . & 0.138 & -0.168 \\
\hline 0.73 & 0.4855 & 0.4870 & 0.4846 & 15 & -0 . & $0.31 \frac{3}{3}$ & -0.188 \\
\hline 0.74 & 0.4984 & 0.5009 & 0.4975 & 0.0025 & -0.0009 & 0.503 & -0.189 \\
\hline 0.75 & 0.5116 & 0.5151 & 0.5106 & 0.0035 & -0.0010 & $0.68 \%$ & $-0.19 \frac{3}{3}$ \\
\hline 0.76 & 0.5250 & 0.5296 & 0.5240 & 0.0046 & -0.0010 & 0.88 영 & -0.203 \\
\hline 0.77 & 0.5387 & 0.5444 & 0.5376 & 0.0057 & -0.0011 & 1.068 & $-0.20 \frac{2}{3}$ \\
\hline 0.78 & 26 & 0.5596 & 0.5515 & 0.0070 & -0.0011 & 1.273 & -0.208 \\
\hline 0.79 & 0.5669 & 0.5751 & 0.5657 & 0.0082 & -0.0012 & 1.458 & -0.218 \\
\hline 0.80 & 0.5814 & 0.5910 & 0.5802 & 0.0096 & -0.0012 & $1.65 \mathrm{~g}$ & $-0.21 \frac{3}{3}$ \\
\hline
\end{tabular}

Table 4.1. Estimation Results and Comparison with Basmann et al. (Cont.) 


\begin{tabular}{|c|c|c|c|c|c|c|c|}
\hline & & \multicolumn{2}{|c|}{ Estimation } & \multicolumn{4}{|c|}{ Residuals } \\
\hline 2 & $L(z)$ & Basmann & Gamma & Basmann & Gamma & Basmann & Gamma \\
\hline 0.81 & 0.5962 & 0.6073 & 0.5950 & 0.0111 & -0.0012 & $1.86 z$ & -0.20 \\
\hline 0.82 & 3.6114 & 0.6239 & $c .6102$ & 0.0125 & -0.0012 & 2.048 & -0.20 \\
\hline 0.33 & 0.6268 & 0.6409 & 0.6257 & 0.0141 & -0.0011 & $2.25 ?$ & -0.18 : \\
\hline 0.34 & 0.6426 & 0.6583 & 0.6416 & 0.0157 & -0.0010 & 2.443 & -0.16 \\
\hline 0.35 & 0.6587 & 0.6762 & 0.6579 & 0.0175 & -0.0008 & 2.668 & -0.13 \\
\hline 0.36 & 0.6752 & 0.6944 & 0.6746 & 0.0192 & -0.0006 & 2.845 & -0.09 \\
\hline 0.37 & 0.6922 & 0.7130 & 0.6917 & 0.0208 & -0.0005 & 3.003 & -0.07 \\
\hline 0.38 & 0.7096 & 0.7321 & 0.7094 & 0.0225 & -0.0002 & 3.17 3 & $-0.03=$ \\
\hline 0.99 & 0.7275 & 0.7517 & 0.7276 & 0.0242 & 0.0001 & $3.33 \%$ & 0.01 \\
\hline 0.90 & 0.7459 & 0.7717 & 0.7464 & 250 & 0.0 & 3.463 & 0.063 \\
\hline 0.91 & 0.7649 & 0.7922 & 0.7658 & 0.0273 & 0.0009 & $3.57 \%$ & $0.12 \xi$ \\
\hline 0.92 & 0.7846 & 0.8131 & 0.7859 & 0.0285 & 0.0013 & 3.638 & 0.177 \\
\hline 0.93 & 0.8052 & 0.8346 & 0.8068 & 0.0294 & 0.0016 & 3.653 & $0.20 \xi$ \\
\hline 0.94 & 0.8266 & 0.8566 & 0.8286 & 0.0300 & 0.0020 & 3.638 & $0.24 \%$ \\
\hline 0.95 & 0.8491 & 0.8791 & 0.8513 & 0.0300 & 0.0022 & 3.53 3 & 0.267 \\
\hline 0.96 & 0.8731 & 0.9021 & 0.8752 & 0.0290 & 0.0021 & 3.323 & 0.248 \\
\hline 0.97 & 0.8989 & 0.9257 & 0.9004 & 0.0268 & 0.0015 & 2.988 & 0.168 \\
\hline 0.98 & 0.9276 & 0.9499 & 0.9271 & 0.0223 & -0.0005 & $2.40 \frac{8}{3}$ & -0.068 \\
\hline 0.99 & 0.9596 & 0.9746 & 0.9556 & 0.0150 & -0.0040 & 1.568 & -0.428 \\
\hline 1.00 & 1.00 & 1.0000 & 1.0000 & 0.0000 & 0.0000 & $0.00 \frac{q}{3}$ & $0.00 \%$ \\
\hline
\end{tabular}

Table 4.1. Estimation Results and Comparison with

Basmann et al. (Cont.)

\begin{tabular}{|lccc|}
\hline & Basmann & \multicolumn{2}{c|}{ Gamma } \\
Absolute & 0.01079 & Non-Linear & Linear \\
Relative & 0.03723 & 0.000131 & 0.000948 \\
\hline
\end{tabular}

Table 4.2. Sum of Squared Residuals 


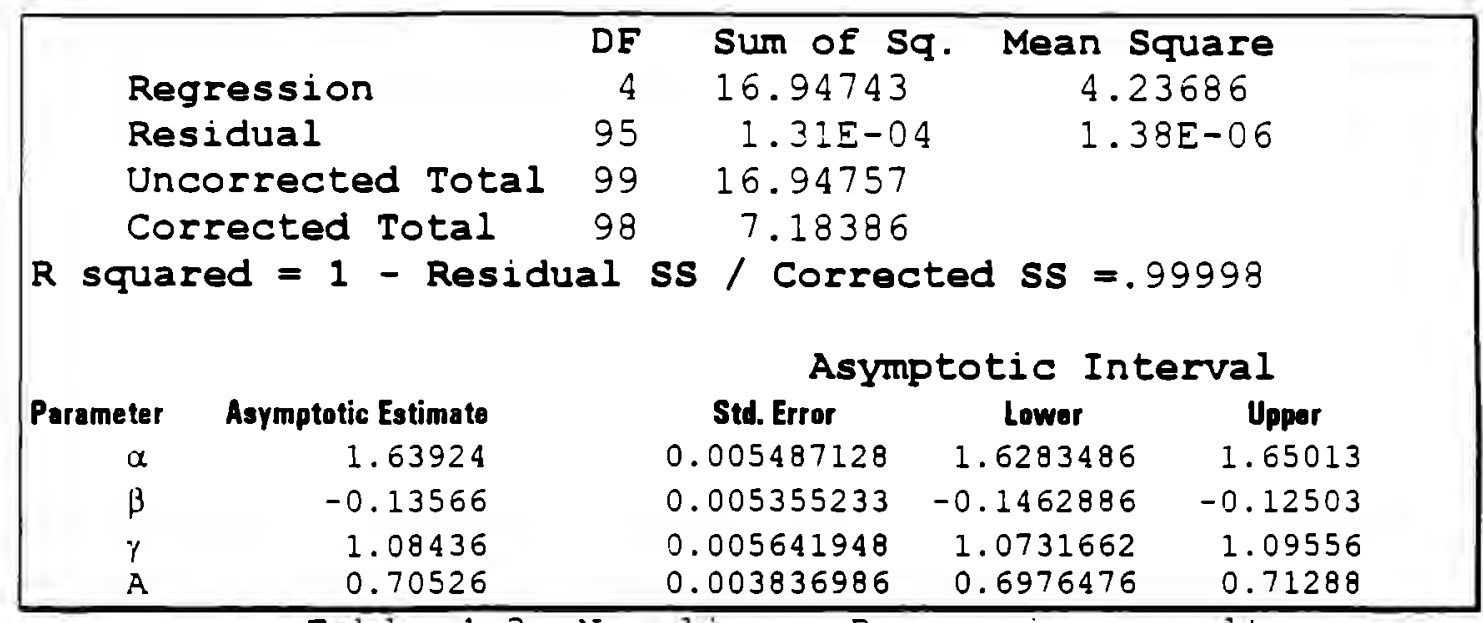

Table 4.3. Non-linear Regression results

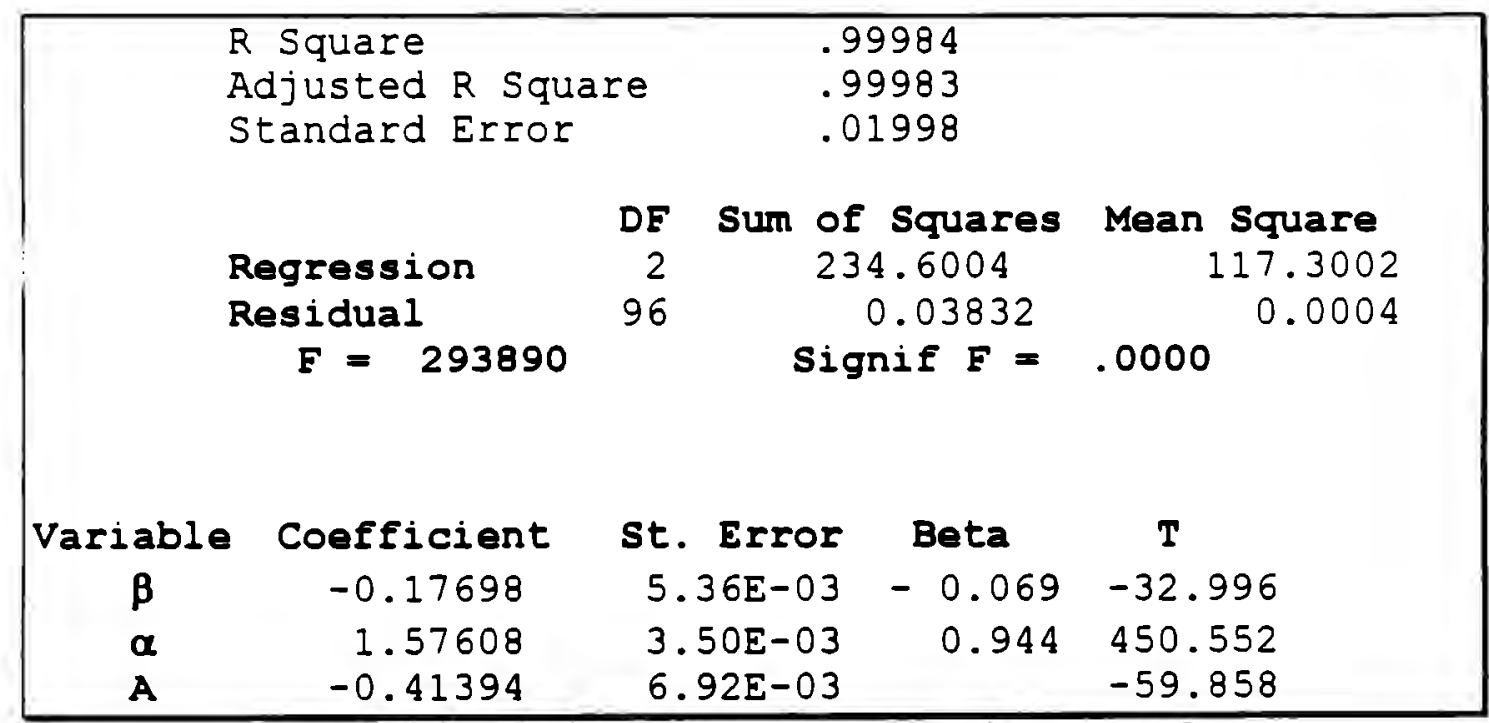

Table 4.4. Linear Regression results 


\begin{tabular}{|c|c|c|c|c|c|c|c|c|c|}
\hline Reg. & $\bar{R}^{2}$ & $F$ & A & $t$ & $\boldsymbol{\alpha}$ & $t$ & $\boldsymbol{\beta}$ & $t$ & Oba \\
\hline I Complete & 0.9997 & 150346 & -0.3674 & 44.9 & 1.598 & 374 & -0.096 & 22 & 99 \\
\hline 2 selected & 0.9997 & 31936 & -0.3312 & 18.5 & 1.620 & 189 & -0.076 & 8 & 21 \\
\hline 3 selected & 0.9998 & 26626 & -0.3178 & 15.47 & 1.629 & 180 & -0.068 & 7 & 11 \\
\hline 4 Selected & 0.9999 & 28989 & -0.3202 & 14.1 & 1.631 & 190 & -0.066 & 7 & 6 \\
\hline 6 Random & 1.0000 & 341470 & -0.3096 & 39.5 & 1.683 & 225 & -0.087 & 22 & 8 \\
\hline 7 Random & 0.9998 & 17335 & -0.3475 & 8.3 & 1.617 & 115 & -0.097 & 3 & 8 \\
\hline a Random & 1.0000 & 355158 & -0.5442 & 38.9 & 1.522 & 236 & -0.257 & 19 & 6 \\
\hline 9 Random & 0.9997 & 7760 & -0.3523 & 8.5 & 1.607 & 65 & -0.092 & 5 & 6 \\
\hline 10 Random & 1.0000 & 115688 & -0.3272 & 13.8 & 1.627 & 246 & -0.089 & 5 & 5 \\
\hline 11 Random & 0.9999 & 10789 & -0.3039 & 10.2 & 1.649 & 77 & -0.074 & 6 & 4 \\
\hline 12 Random & 1.0000 & NA & -0.2662 & NA & 1.728 & NA & -0.068 & NA & 3 \\
\hline 13 Random & 1.0000 & NA & -0.4018 & $\mathrm{NA}$ & 1.570 & NA & -0.131 & NA & 3 \\
\hline \multirow{2}{*}{$\begin{array}{l}\text { Average } \\
\text { std Dev }\end{array}$} & 0.999 & NA & -0.349 & In & 1.624 & $\boldsymbol{N R}$ & -0.101 & \multicolumn{2}{|l|}{$\mathbf{N n}$} \\
\hline & 0.000 & $\mathbf{N R}$ & 0.070 & $\mathbf{N A}$ & 0.052 & $\mathbf{N}$ & 0.053 & $\mathbf{N R}$ & \\
\hline \multicolumn{10}{|c|}{ Table } \\
\hline
\end{tabular}

NOTE: NA = Not Available. $A$ is a function of $\beta$ and $\gamma$ (Cf. linearization algorithm). 


\begin{tabular}{|c|c|c|c|c|c|c|c|c|}
\hline . & Countery & year & I & 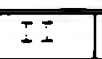 & III & IV & $\mathrm{v}$ & 10 \\
\hline & Argentina & 1970 & 4.4 & 9.7 & 14.1 & 21.5 & 50.3 & 35.2 \\
\hline & Australia & 1975 & 5.4 & 10.0 & 15.0 & 22.5 & 47.1 & 30.5 \\
\hline 3 & Belgium & 1975 & 7.7 & 12.4 & 17.0 & 23.1 & 39.8 & 24.3 \\
\hline 4 & Brazil & 1972 & 2.2 & 5.0 & 9.4 & 17.0 & 66.6 & 50.6 \\
\hline 5 & Canada & 1977 & 3.8 & 10.7 & 17.9 & 25.6 & 42.0 & 26.9 \\
\hline 6 & Chile & 1968 & 4.4 & 9.0 & 13.8 & 21.4 & 51.4 & 34.8 \\
\hline 7 & Denmark & 1976 & 7.4 & 12.6 & 18.3 & 24.2 & 37.5 & 22.4 \\
\hline 8 & Finland & 1977 & 6.8 & 12.8 & 18.7 & 24.9 & 36.8 & 21.2 \\
\hline 9 & France & 1975 & 5.3 & 11.1 & 16.0 & 21.8 & 45.8 & 30.5 \\
\hline 10 & Germany, Fed. Rep. & 1978 & 7.9 & 12.5 & 17.0 & 23.1 & 39.5 & 24.0 \\
\hline 11 & Hong Kong & 1980 & 5.4 & 10.8 & 15.2 & 21.6 & 47.0 & 31.3 \\
\hline 12 & Ireland & 1973 & 7.2 & 13.1 & 16.6 & 23.7 & 39.4 & 25. \\
\hline 13 & Israel & 1979 & 6.0 & 12.0 & 17.7 & 24.4 & 39.9 & 22.6 \\
\hline 14 & Italy & 1977 & 6.2 & 11.3 & 15.9 & 22.7 & 43.9 & 28.1 \\
\hline 15 & Japan & 1979 & 8.7 & 13.2 & 17.5 & 23.1 & 36.8 & 21.2 \\
\hline 16 & Korea, Rep. of & 1976 & 5.7 & 11.2 & 15.4 & 22.4 & 45.3 & 27.5 \\
\hline 17 & Malaysia & 1973 & 3.5 & 7.7 & 12.4 & 20.3 & 56.1 & 39.8 \\
\hline 181 & Mexico & 1977 & 2.9 & 7.0 & 12.0 & 20.4 & 57.7 & 40.6 \\
\hline 191 & Netherlands & 1977 & 8.1 & 13.7 & 17.9 & 23.3 & 37.0 & 22.1 \\
\hline 201 & Norway & 1970 & 6.3 & 12.9 & 18.8 & 24.7 & 37.3 & 22.2 \\
\hline 21 & Panama & 1970 & 2.0 & 5.2 & $11: 0$ & 20.0 & 61.8 & 44.2 \\
\hline 22 & Spain & 1974 & 6.0 & 11.8 & 16.9 & 23.1 & 42.2 & 26.7 \\
\hline 23 & Sweden & 1979 & 7.2 & 12.8 & 17.4 & 25.4 & 37.2 & 21.2 \\
\hline 24 & Trinidad \& Toba & 1975 & 4.2 & 9.1 & 13.9 & 22.8 & 50.0 & 31.8 \\
\hline 250 & United Kingdom & 1979 & 7.0 & 11.5 & 17.0 & 24.8 & 39.7 & 23.4 \\
\hline $26[5$ & United States & 1978 & 4.6 & 8.9 & 14.1 & 22.1 & 50.3 & 33.4 \\
\hline $27 \sqrt{7}$ & Venezuela & 1970 & 3.0 & 7.3 & 12.9 & 22.8 & 54.0 & 35.7 \\
\hline 28 & Yugoslavia & 1978 & 6.6 & 12.1 & 18.7 & 23.9 & 38.7 & 22.9 \\
\hline
\end{tabular}

Table 4.6. Income Distribution Data for Cross-Country study

NOTE: Roman numerals show the quintiles. 10 means the income received by the top decile. The year refers to the income distribution data. 


\begin{tabular}{|c|c|c|c|c|}
\hline No.1 & Country & $\alpha$ & $\vec{\beta}$ & $y$ \\
\hline & Argentina & 1.5878 & -0.1659 & 1.0280 \\
\hline 2 & Australia & 1.4488 & -0.2276 & 1.0640 \\
\hline 3 & $\overline{\text { Belgium }}$ & 1.3346 & -0.1802 & 1.0863 \\
\hline & Brazil & 1.5539 & -0.4629 & 1.0493 \\
\hline 5 & Canada & 1.9183 & -0.0430 & 1.0117 \\
\hline 6 & Chile & 1.5596 & -0.1860 & 1.0294 \\
\hline 7 & Denmark & 1.4023 & -0.1804 & 1.1321 \\
\hline 8 & Finland & 1.4926 & -0.1609 & 1.1584 \\
\hline 9 & Erance & 1.5674 & -0.1169 & 1.0247 \\
\hline 10 & Germany, Eed. & 1.3151 & -0.1888 & 1.0941 \\
\hline 11 & Hong Kong & 1.5034 & -0.1570 & $1.02: 9$ \\
\hline 12 & Ireland & 1.4363 & -0.1011 & 1.0366 \\
\hline 13 & Israel & 1.5226 & -0.1985 & 1.1523 \\
\hline 14 & Italy & 1.4208 & -0.1970 & 1.0714 \\
\hline 15 & Japan & 1.2524 & -0.2532 & 1.1819 \\
\hline 16 & Korea, Rep. of & 1.4557 & -0.2204 & 1.0855 \\
\hline 17 & Malaysia & 1.5604 & -0.2939 & 1.0489 \\
\hline 18 & Mexico & 1.6606 & -0.3055 & 1.0495 \\
\hline 19 & Netherlands & 1.3942 & -0.0957 & 1.0504 \\
\hline 20 & Norway & 1.5929 & -0.0714 & 1.0495 \\
\hline 21 & Panama & $1 . \overline{7924}$ & -0.3815 & 1.0551 \\
\hline 22 & Spain & 1.5190 & -0.1286 & 1.0486 \\
\hline 23 & Sweden & 1.3734 & -0.3207 & 1.2957 \\
\hline 24 & Trinidad \& Toba & 1.5212 & -0.3422 & 1.1120 \\
\hline 25 & United Kingdom & 1.2845 & -0.4868 & 1.3334 \\
\hline 26 & United States & 1.4434 & -0.3396 & 1.0963 \\
\hline 27 & Venezuela & 1.6648 & -0.3755 & 1.0979 \\
\hline 28 & Yugoslavia & 1.489 & -0.1550 & 1.109 \\
\hline
\end{tabular}

Table $4.7 . \alpha, \beta$ and $\gamma$ for different countries 


\begin{tabular}{|c|c|c|c|c|c|c|c|c|}
\hline Decil & 1950 & 1958 & 1963 & 1968 & 1972 & 1977 & 1984 & 1989 \\
\hline I & 0.0243 & 0.0232 & 0.0169 & 0.0121 & 0.0142 & 0.0108 & 0.0170 & 0.0114 \\
\hline$=$ & 0.0560 & 0.0553 & 0.0366 & 0.0342 & 0.0376 & 0.0329 & 0.0470 & 0.0362 \\
\hline$=\bar{z}$ & 10.0873 & 0.0959 & 0.0708 & 0.0646 & 0.0725 & 0.0652 & 0.0879 & 0.0714 \\
\hline$I V$ & 0.1307 & 0.1457 & 0.1050 & 0.1069 & 0.1179 & 0.1094 & 0.1400 & 0.1170 \\
\hline $\bar{T}$ & 0.1800 & 0.2059 & 0.1564 & 0.1576 & 0.1725 & 0.1667 & 0.2041 & 0.1746 \\
\hline$T I$ & 0.2396 & 0.2808 & 0.2172 & 0.2222 & 0.2549 & 0.2382 & 0.2834 & 0.2467 \\
\hline VII & 0.3100 & 0.3637 & 0.2957 & 0.3050 & 0.3373 & 0.3293 & 0.3830 & 0.3369 \\
\hline VIII & 0.4063 & 0.4710 & 0.4195 & 0.4189 & 0.4417 & 0.4491 & 0.5091 & 0.4511 \\
\hline$I X$ & 0.5452 & 0.6430 & 0.5840 & 0.5795 & 0.6078 & 0.6200 & 0.6793 & 0.6104 \\
\hline$x$ & 1.0000 & 1.0000 & 1.0000 & 1.0000 & 1.0000 & 1.0000 & 1.0000 & 1.0000 \\
\hline
\end{tabular}

NOTE: Data of income per deciles. Cumulative percentage of income. $1=100$ 各

\begin{tabular}{|c|c|c|c|}
\hline YENR & $\boldsymbol{\alpha}$ & $\boldsymbol{\beta}$ & $\boldsymbol{\gamma}$ \\
\hline 1950 & 1.2149 & -0.2648 & 1.0198 \\
\hline 1958 & 1.2917 & -0.2932 & 1.0536 \\
\hline 1963 & 1.4093 & -0.3931 & 1.0604 \\
\hline 1968 & 1.5929 & -0.2580 & 1.0304 \\
\hline 1972 & 1.6144 & -0.1929 & 1.0220 \\
\hline 1977 & 1.6994 & -0.2300 & 1.0376 \\
\hline 1984 & 1.5290 & -0.2441 & 1.0667 \\
\hline 1989 & 1.6694 & -0.1814 & 1.0211 \\
\hline
\end{tabular}
Table 4.9. $\boldsymbol{\alpha}, \boldsymbol{\beta}$ and $\gamma$ for Mexico




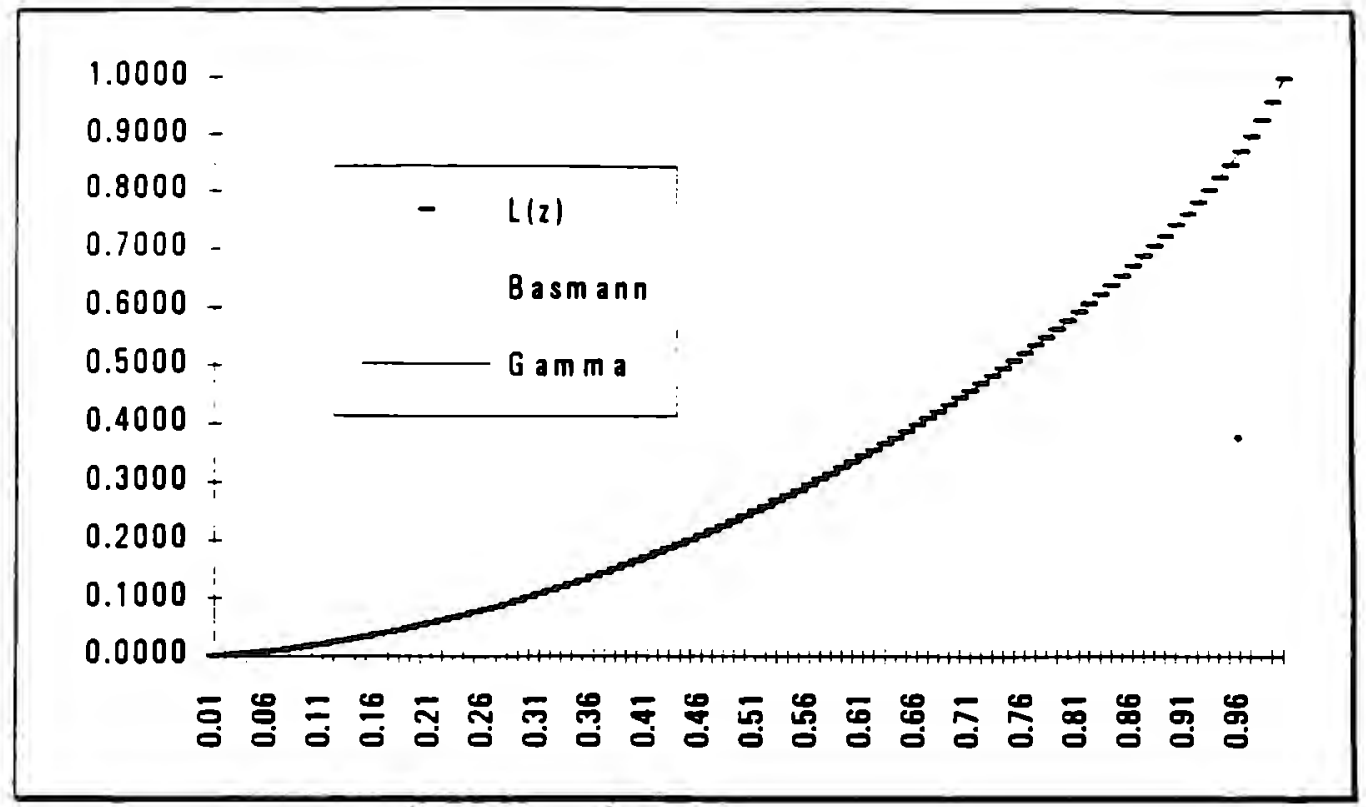

Eigure 4.1. Lorenz curves

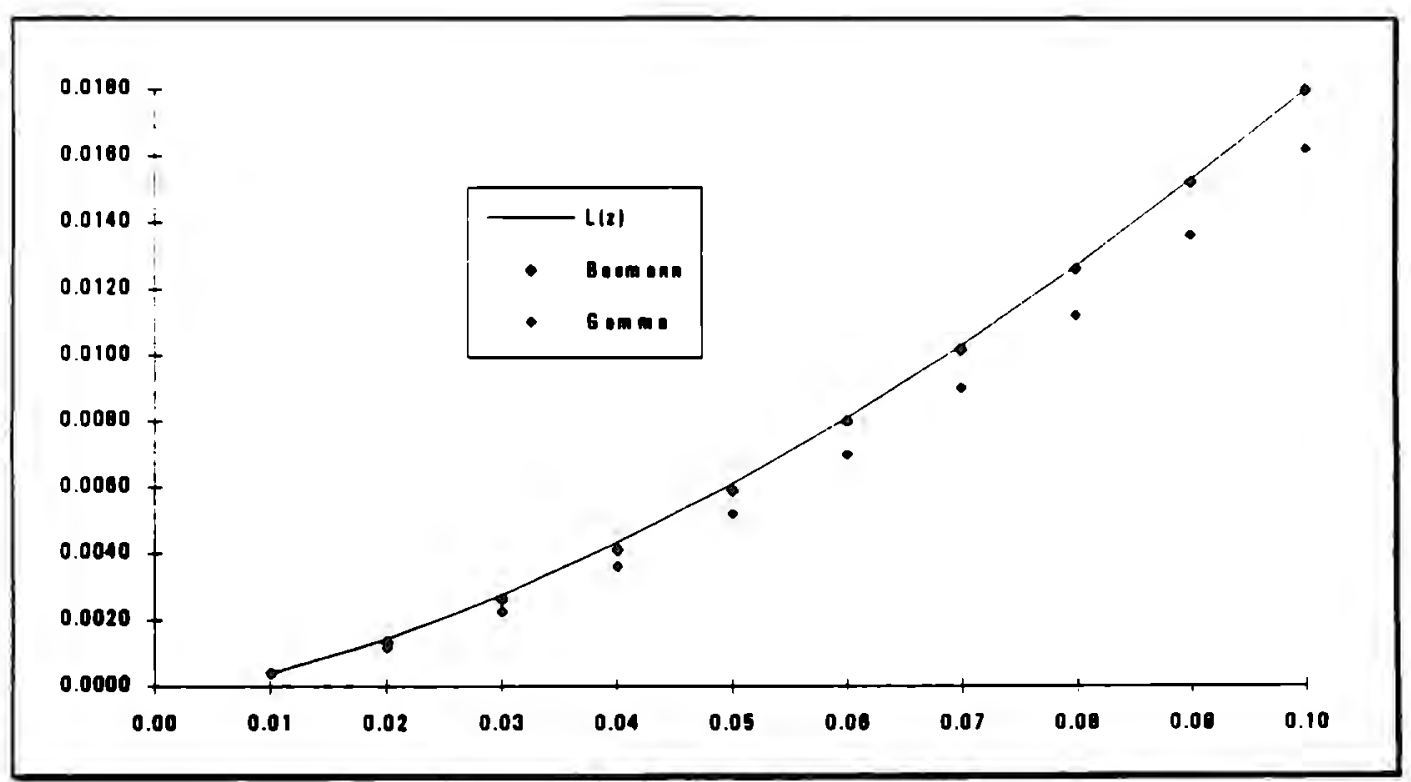

Figure 4.2. First Decile 


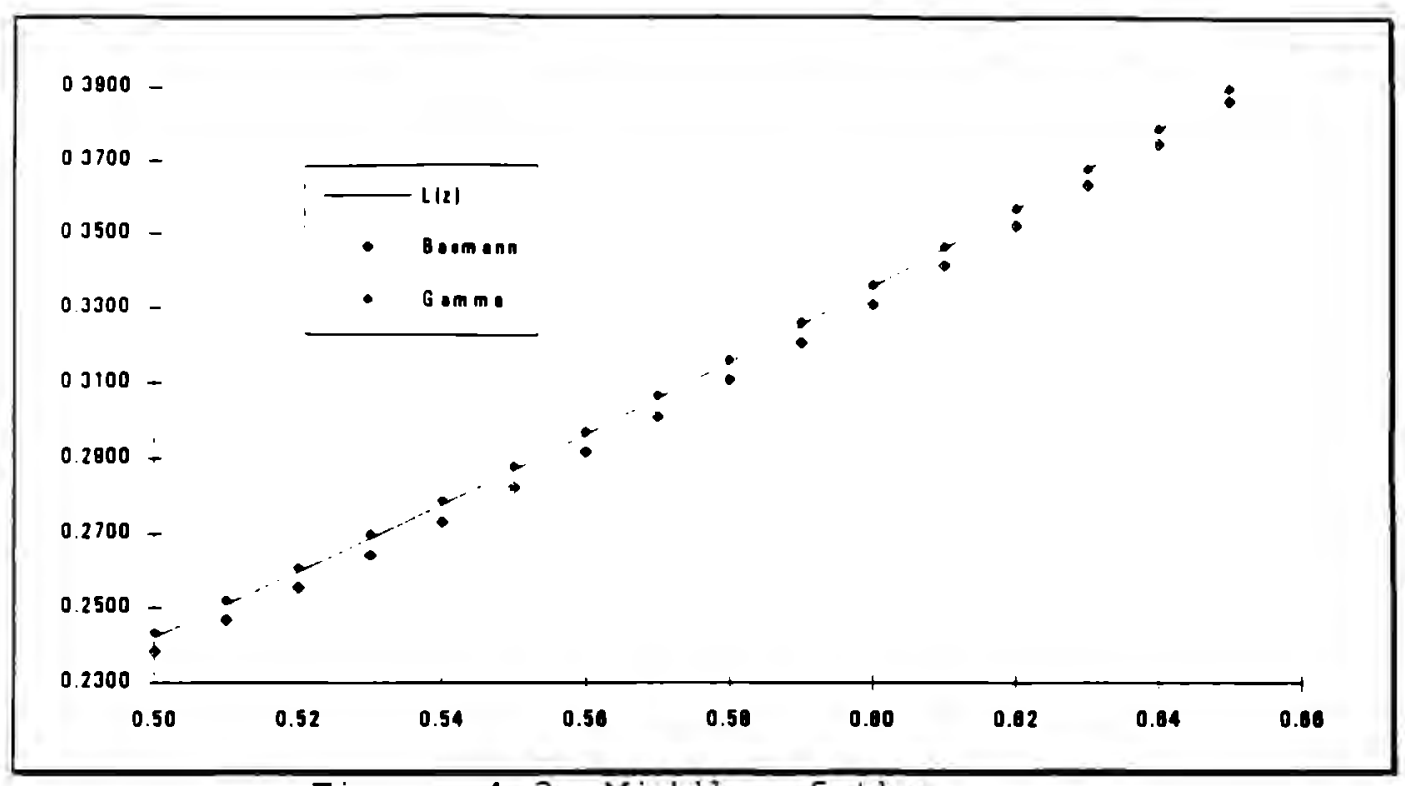

Figure 4.3 . Middle of the curves

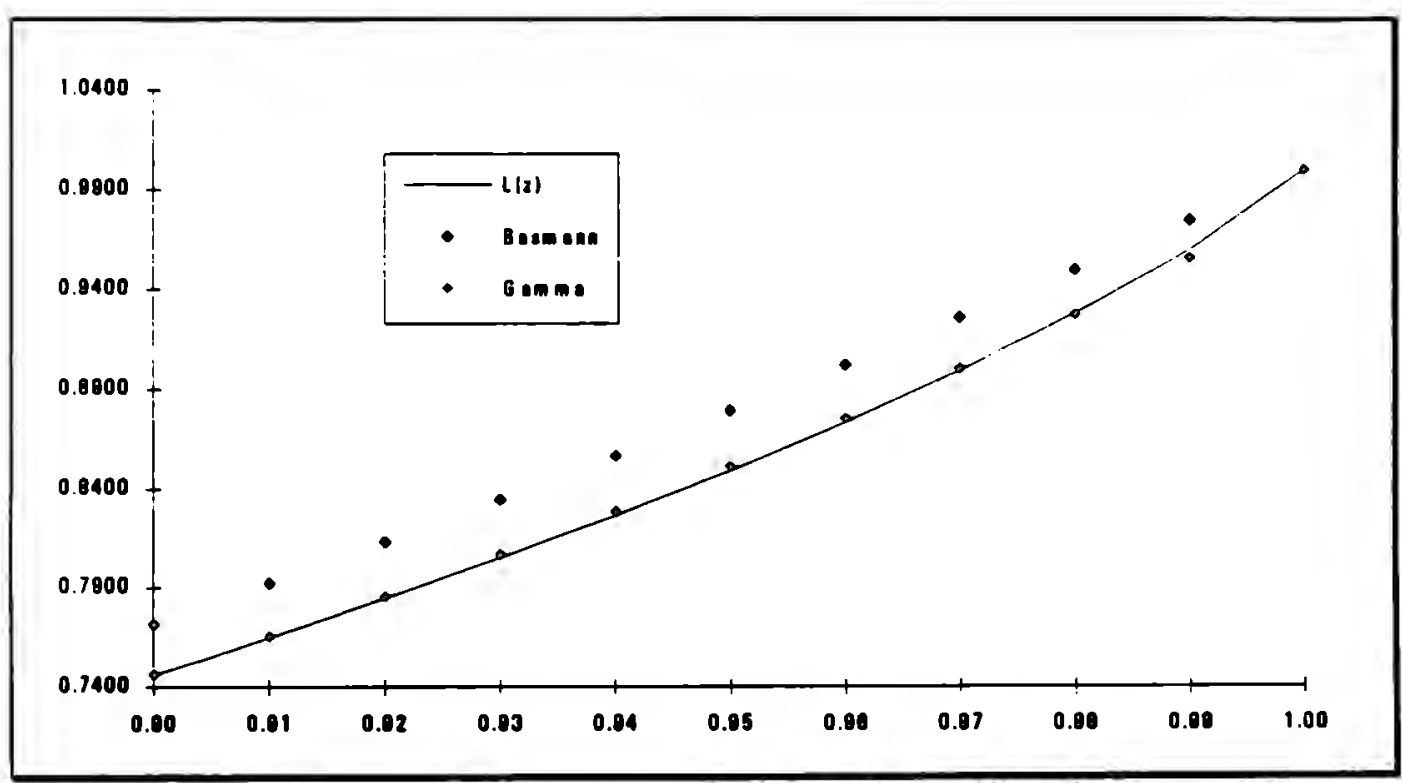

Figure 4.4. Top of the distribution 


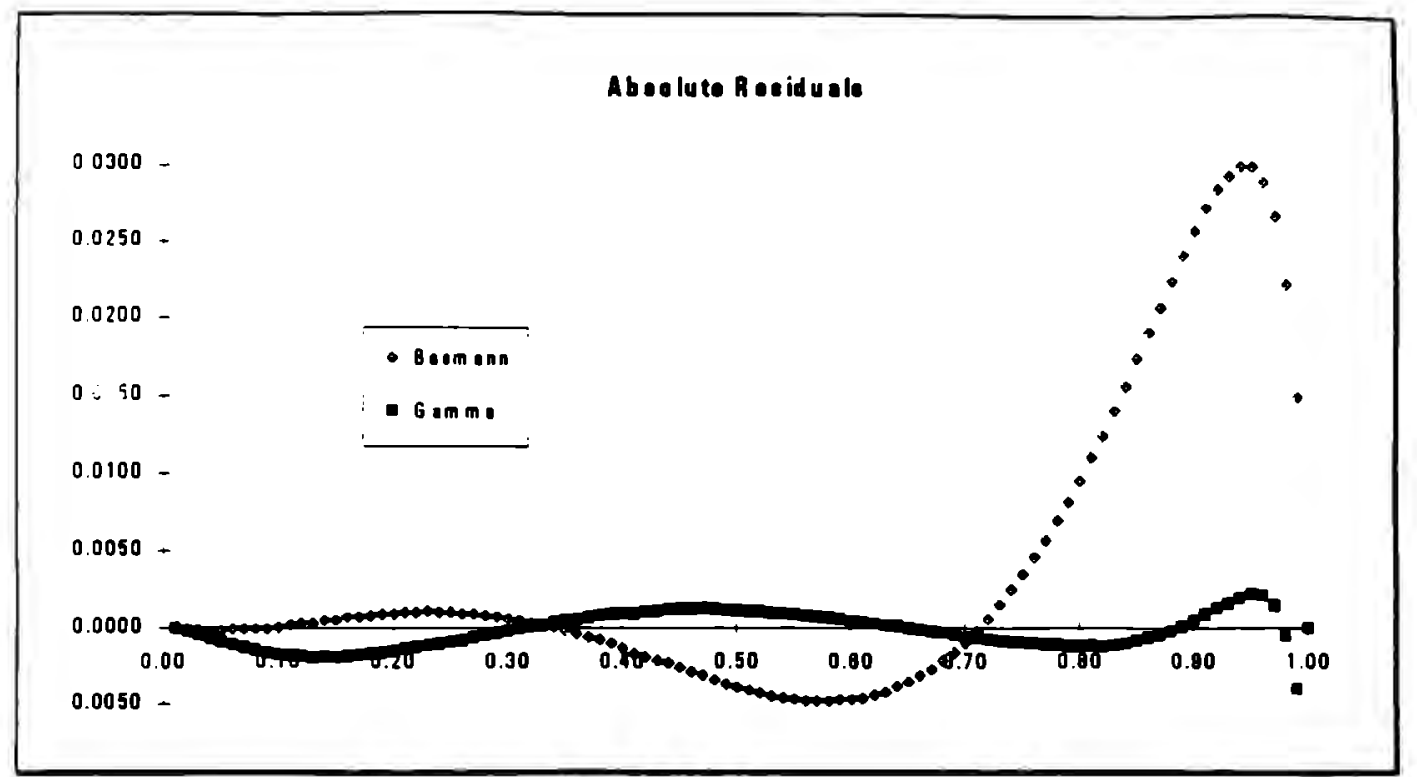

Eigure 4.5. Absolute Residuals

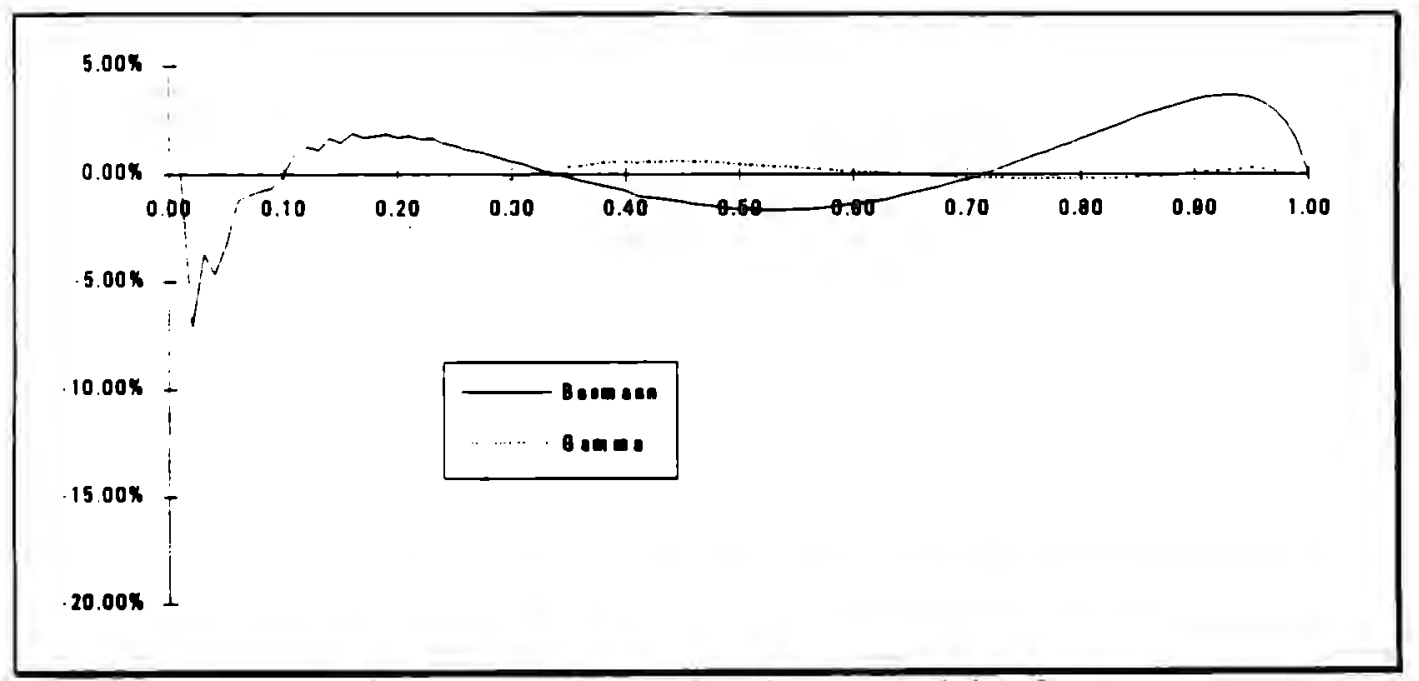

Figure 4.6. Relative Residuals 


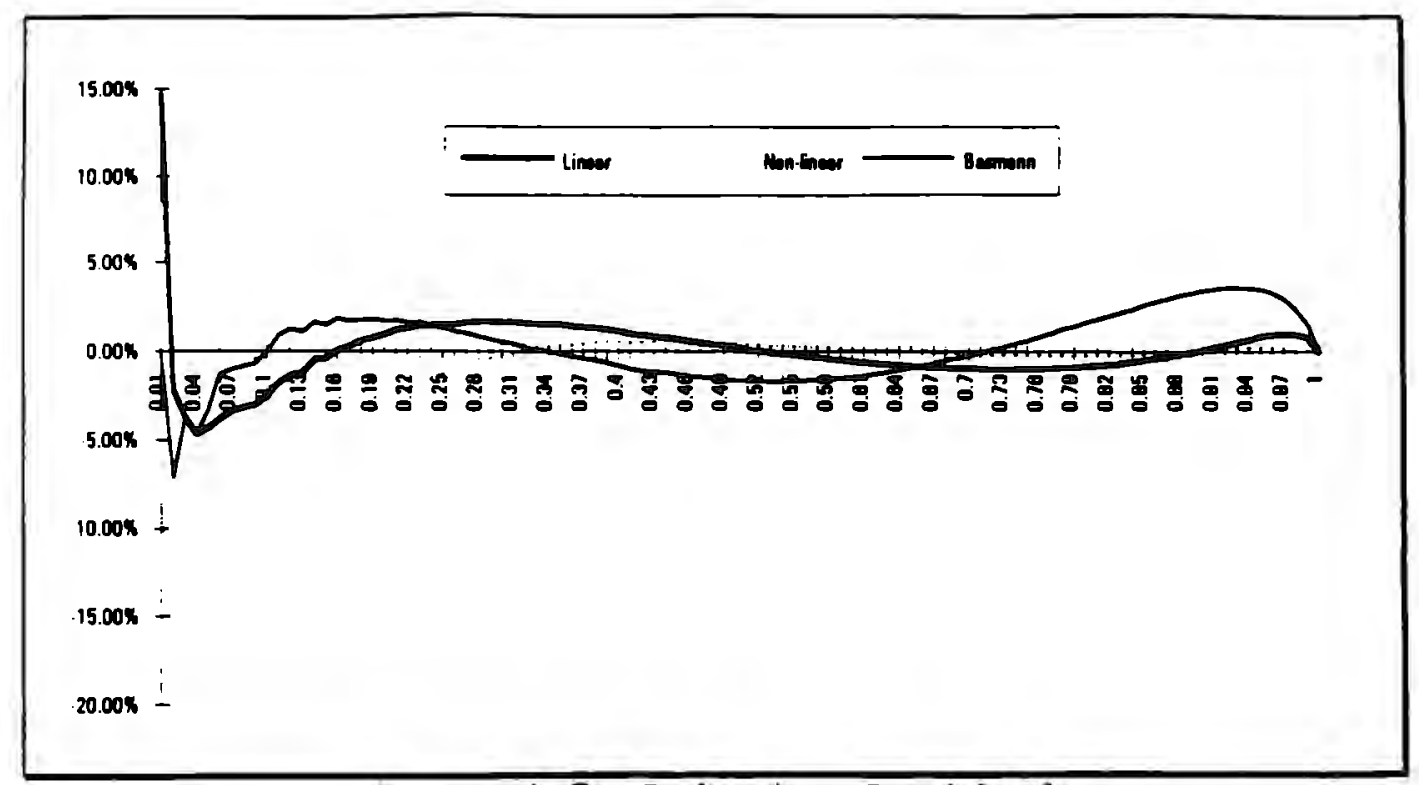

Figure 4.7. Relative Residuals 
CHAPTER 5

EXOGENOUS GROWTH AND INCOME JISTRIBUTION.

From the overlapping generations model presented in chapter 3, it is clear that growth depends critically on income distribution. In this chapter we incorporate a function that simulates income distribution in an economic growth model to shed some light on this issue.

I. A Simple Model

The model has the following characteristics: we have an economy with many individuals that use their income either to consume or save. Savings become investment in physical capital and are used in future production, so the alternative for the consumers is between present and future consumption. Production is obtained from capital stock and there is a national production function. Individual's income is attained through the income distribution function, which was obtained in the previous chapter. In consequence, every agent has different income that means different decisions about present and future consumption have to be made. 
We have a set of individuals indexed by $i=[0,1]$. This index can be understood as a percentage measure of the population, sorted, as is usual in income distribution data, by their relative income. Thus, an agent with an income greater than 808 of the population would have an index $i=0.8$. Every individual maximizes an intertemporal utility function

$$
v_{1}^{i}=\int_{0}^{\infty} e^{-p t} U\left(c_{t}^{i}\right) d t
$$

where $U(\cdot)$ has the usual properties of a well-behaved utility function, and $\rho$ is the discount factor. They maximize consumption, then, subject to the constraint

$$
y_{t}^{i}=c_{t}^{i}+\dot{k}_{t}^{i}
$$

where income $y$ is distributed between consumption (c) and savings $(k)$. To define individuals' income, we will use the Lorenz curve,

$$
z_{t}^{\prime}=i^{\alpha_{1}}\left(\frac{\gamma-i}{\gamma-1}\right)^{\beta_{1}} \quad 4,3=(5.3)
$$


which describes cumulative income. Individual income can be inferred from the derivative against $i$ :

$$
\frac{\hat{c} z_{t}^{\prime}}{\hat{c} i}=z_{t}^{\prime}\left(\frac{\alpha_{t}}{i}-\frac{\beta_{t}}{\gamma-i}\right)
$$

for example, if we are analyzing population by percentiles, the income of the agent with index $i=0.8$ is approximated by this derivative evaluated at 0.8 times $\Delta i$, which is equal to 0.01 . Following this argument, individual income $y$ is defined as

$$
y_{t}^{i}=z_{t}^{i} Y_{t}\left(\frac{\alpha}{i}-\frac{\beta}{\gamma-i}\right) \Delta i
$$

that is, the national income ( $Y$ ) multiplied by the effect of income distribution as measured by the Lorenz curve. This equation reflects the income received by an individual depending on his position in the distribution, multiplied by the amount produced. National income comes from a normal production function like

$$
Y_{t}=A k_{i}^{\theta}
$$


where $k$ is measured in efficiency units, allowing us to avoid the use of another variable. Note that from (5.5) and (5.6), an increase in national income will have different effects on individuals, since it is filtered through the income distribution function. This mechanism leads to different incentives to increase national product, since for poor people a $1 \frac{\partial}{3}$ increase in GNP represents much less than 1 o increase in their earnings, if no redistribution takes place. On the other hand, rich agents will be much more interested in GNP increase, since they will capture most of the national growth.

This point deserves some time to analyze it. Under a totally uniform income distribution, every individual will get the same returns from the capital invested. On the other hand, under a non-uniform income distribution, like the one we have here, returns on individuals' capital will differ because of the filtering effect of income distribution. What is happening here is that the income distribution function, which includes much more than only income, is implicitly defining that agents in certain positions in the distribution have less opportunities or abilities to invest, and hence, receive smaller returns on their capital. 
The (optimal) growth in consumption that these agents will find is also agent-specific, since the different shade: price of capital will determine a different consumption/savings ratio for every individual. Another interesting point is that the lower the agent is in the distribution, the more prone he will be $t$ : consume in the present since the returns on his capital will be smaller than for all the agents above him in the distribution. This may explain the "conventional wisdom" that often impute poor people the excessive desire to consume and not to save. Income distribution relative position of individuals affects income through $z$, which is defined as

$$
z_{t}^{\prime}=i^{\alpha_{1}}\left(\frac{\gamma_{t}-i}{\gamma_{t}-1}\right)^{\beta_{t}}
$$

where the parameters $\alpha, \beta$ and $\gamma$ depend on diverse economic variables, like income, capital stock or capital accumulation. In this paper I will assume that $\alpha$ and $\beta$ depend on income, while $\gamma$ is constant ${ }^{1}$ :

Empirical research supports this selection. Income seems to be the variable that affects $\alpha$ and $\beta$, while $\gamma$ is almost constant over a wide range of countries. Nevertheless, if we use capital stock or capital accumulation, results are quite similar, although the model becomes more complex. 


$$
\begin{aligned}
\alpha & =\alpha(y) \\
\beta & =\beta(y, \gamma) \\
\gamma & =\bar{\gamma}
\end{aligned}
$$

The solution of this model can be found using the current value Hamilton: $=n^{2}$ :

$$
H\left(k^{\prime}, \lambda, c^{i}, t\right)=U\left(c_{t}^{\prime}\right)+\lambda \dot{k}_{t}^{i}
$$

where (from $(5.2),(5.5)$ and $(5.6)$ )

$$
\dot{k}_{i}^{\prime}=z_{i}^{i} A k_{\imath}^{\theta}\left(\frac{\alpha}{i}-\frac{\beta}{\gamma-i}\right) \Delta i-c_{\imath}^{i}
$$

that represents the sum of current period utility and capital accumulation, valued at "price" $\lambda$. An optimal allocation must maximize $H$ at each date $t$, if $\lambda(t)$ is appropriately selected. ${ }^{3}$ The first order condition for maximizing (5.9) is

$$
U_{c}^{\prime}=\lambda
$$

-See Kamien and Schwartz (1991) $\left(5.1^{0}\right)$, is 'The only restrictions are that $(7)$ and $(8)$ and continuous over $t$. (Kamien and Schwartz (1991)) 
and the price $\lambda$, must follow

$$
\dot{\lambda}-\rho \lambda=-\frac{\partial H}{\partial k_{t}^{\prime}}
$$

These equations, (5.11) and (5.12) are a pair of differential equations in $k$ and $\lambda^{4}$. We can find a family of solutions which satisfy the initial value $k(0)$. The unique member of this family that satisfies the transversality condition

$$
\lim _{t \rightarrow \infty} e^{-\rho t} \lambda k_{t}^{i}=0
$$

will be the optimal path. ${ }^{5}$ From these equations, we can construct the balanced growth path, where the rates of growth of capital, consumption and $\lambda$ are constant. Solving (5.12) and rearranging, we obtain 6

$$
\frac{\dot{\lambda}}{\lambda}=\rho-A \theta k_{t}^{\theta-1} z_{t}^{i}\left(\frac{\alpha}{i}-\frac{\beta}{\gamma-i}\right) \Delta \mathbf{M}_{t}^{i}
$$

where

"In general, I will omit the time subindex in $\lambda$.

isee also Kamien and Schwartz (1991) $\rightarrow$

'For detailed calculations, see appendix $A$. 


$$
\mathbf{M}_{t}^{\prime}=1+a \ln i+b \ln \frac{\gamma-i}{\gamma-1}+\frac{a-b(\gamma-i)}{\alpha_{i}-\beta(\gamma-i)}
$$

and

$$
a=A k_{\imath}^{\theta} \alpha_{y}^{\prime} \quad \text { and } \quad b=A k_{t}^{\theta} \beta_{y}^{\prime}
$$

wi._ch has a very interesting intuitive interpretation. The left-hand side of (5.14) is the percentage rate of growth of the "shadow" price of future consumption. In the standard case of growth theory, i.e., for an egalitarian income distribution, this rate is equivalent to the (discounted) marginal productivity of capital. In the case of a non-egalitarian distribution, the right-hand side is no longer the marginal productivity, since income distribution "filters" the effect of capital on the income of individuals. Depending on the individual's relative position in the income distribution, the marginal productivity of his capital will be different. This is the meaning of $\mathbf{M}^{i}$. If we take equations (5.14) and (5.15) we have

$$
\rho-\frac{\dot{\lambda}}{\lambda}=A \theta k_{t}^{\theta-1} z_{t}^{\prime}\left(\frac{\alpha}{i}-\frac{\beta}{\gamma-i}\right) \Delta i\left[1+a \ln i+b \ln \frac{\gamma-i}{\gamma-1}+\frac{a / i-b /(\gamma-i)}{\alpha / i-\beta /(\gamma-i)}\right]
$$


Note that the term outside the brackets in the right-hand side of the equation is similar to the definition of individual's income, that is, the derivative of the Lorenz curve. The rest of the right-hand side is

$$
A \theta k_{t}^{\theta-1} z^{\prime}\left(\frac{\alpha}{i}-\frac{\beta}{\gamma-i}\right) \Delta i\left[a \ln i+b \ln \frac{\gamma-i}{\gamma-1}\right]+A \theta k_{t}^{\theta-1} z_{t}^{\prime} \Delta i(a / i-b /(\gamma-i))
$$

which is exactly the derivative of individual's income against national income, times $A \theta k_{t}^{\theta-1} .^{7}$ Then, equation (5.14) may also be written as

$$
\rho-\frac{\dot{\lambda}}{\lambda}=A \theta k_{t}^{\theta-1}\left[\frac{\partial z_{t}^{i}}{\partial i}+\frac{\partial y_{t}^{i}}{\partial y}\right] \Delta i=A \theta k_{t}^{\theta-1}\left[\frac{\partial z_{t}^{i}}{\partial i}+A k^{\theta} \frac{\partial^{2} z_{t}^{i}}{\partial i \partial y}\right] \Delta i
$$

that is, marginal productivity of capital is affected by two different forces: First, the relative position of the individual in the income distribution; and second, the marginal relative position of the individual, that is, the sensitivity of this individual's income to changes in national income. Then, if national income goes up $1 \%$, individual's income will increase less (more) than 18 if and only if the mixed effect of his actual position and

See the appendix for details. 
its sensitivity to changes in income is less (more) than one.

We still have a term in this last equation that needs to be analyzed. The percentage change in the shadow price may be eliminated by differentiating (5.11). However, we need to impose some restriction on the utility function defined in (5.1), that is, we require the utility function to have a constant intertemporal elasticity of substitution. This is a normal procedure in order to have simple but solvable equations (Lucas, 1988).

Thus, we have

$$
\frac{\dot{\lambda}}{\lambda}=\frac{U^{\prime \prime}}{U^{\prime}} \dot{c}_{t}^{\prime}=-\sigma \frac{\dot{c}_{t}^{i}}{c_{t}^{i}}=-\sigma \chi_{t}^{i}
$$

where $\sigma$ is the intertemporal elasticity of substitution. Equating (5.14) and (5.18), we obtain

$$
A \theta k_{t}^{\theta-1} z_{t}^{i}\left(\frac{\alpha}{i}-\frac{\beta}{\gamma-i}\right) \Delta i \mathbf{M}_{t}^{i}=\rho+\sigma \chi_{t}^{i}
$$

If we evaluate this equation for the income of the whole country, we get 


$$
A \theta k_{t}^{\theta-1}=\rho+\sigma \chi
$$

that is, the marginal productivity of capital must equal $\rho$ $+\sigma \chi$ in the equilibrium path, where $\chi$ represents the percentual change in consumption in balanced growth. This is the standard result in exogenous growth theory (see Lucas(1988)). Nevertheless, what we have in this case is that .the growth in consumption depends on the marginal productivity affected by income distribution.

As we have stated before, under a totally uniform income distribution, every individual will get the same returns from the capital invested. However, under a nonuniform income distribution, equation (5.14)) shows that the shadow price of capital will be àgent-specific. Moreover, equation (5.19) shows that capital exhibits different marginal productivities depending on the position of the agent in the distribution.

The (optimal) growth in consumption is also agentspecific, since the different shadow price of capital will determine a different consumption/savings ratio for every individual. Focusing on the rate of growth, differentiate $(5.20)$ to obtain 


$$
x=\frac{\mu}{1-\theta}
$$

where $\mu$ is the rate of (exogenous) technical progress. The effect of income distribution on the rate of growth can be seen easily if we make the following argument: since $A \theta k_{t}^{\theta-1}$ is constant across individuals ${ }^{8}$, then for any $i, j$ the following equation must hold

$$
\frac{\left(\rho+\sigma \chi_{i}^{i}\right)}{z_{t}^{\prime}\left(\frac{\alpha}{i}-\frac{\beta}{\gamma-i}\right) \Delta \mathbf{M}^{i}}=\frac{\left(\rho+\sigma \chi_{i}^{j}\right)}{z_{t}^{j}\left(\frac{\alpha}{j}-\frac{\beta}{\gamma-j}\right) \Delta i \mathbf{M}^{i}}
$$

which, specifically, for $j=1$,

$$
\left(\alpha-\frac{\beta}{\gamma-1}\right)\left(\rho+\sigma \chi_{l}^{i}\right)=(\rho+\sigma \chi) z_{t}^{i}\left(\frac{\alpha}{i}-\frac{\beta}{\gamma-i}\right) \Delta \mathbf{M}^{i}
$$

and, substituting (5.21),

'Since it is the marginal produtivity of the nation's stock of capital. 
$\frac{\dot{c}_{1}}{c_{1}}=\left[\sigma\left(\alpha-\frac{\beta}{\gamma-1}\right)\right]^{-1}\left[\left(z_{i}^{\prime}\left(\frac{\alpha}{i}-\frac{\beta}{\gamma-i}\right) \Delta \mathbf{M}^{\prime}\right)\left(\rho+\sigma \frac{\mu}{1-\theta}\right)-\left(\alpha-\frac{\beta}{\gamma-1}\right) \rho\right]$

(5.22) not . only defines the rate of growth for every individual, but also can be used to find the average rate of growth in the whole country.

\section{Dynamics of Income Distribution}

In order to understand clearly this last equation, we will first examine the behavior of $\mathbf{M}^{2}$, as defined in (5.17). Let us first analyze $\frac{\partial z_{t}^{i}}{\partial i}$. This is the mobility function introduced in the previous chapter. In a sense, this function measures the perceived difficulty of moving up in the distribution, of increasing the individual's relative to the national income. This function is always non-negative, since $\beta$ is always less than or equal to zero, meaning that moving up in the income distribution is always costly. Moreover, it is monotonically increasing, since the higher an individual stands in the distribution of income, the harder for him to move further up. 
On the other hand, $A k^{\theta} \frac{\partial^{2} z_{l}^{\prime}}{\partial i \partial y}$ is identical to $\frac{\partial y^{\prime}}{\partial y}$, that is the sensitivity of individual's income to changes in national income. This effect can also be decomposed to interpret it:

$$
A k^{\ominus} \frac{\hat{c}^{2} z_{t}^{\prime}}{\hat{\partial} i \dot{c} y}=z_{i}^{\prime}\left[\left(\frac{\alpha}{i}-\frac{\beta}{\gamma-i}\right) d i\left(a \ln i+b \ln \frac{\gamma-i}{\gamma-1}\right)+(a / i-b /(\gamma-i)) d i\right]
$$

the first term within the brackets may take any value, since the term $a \ln i+b \ln \left(\frac{\gamma-i}{\gamma-1}\right)$ may have any sign and value, provided that $\ln i$ is non-positive $(i \sim[0,1])$ ranging from minus infinity to zero and $\ln \left(\frac{\gamma-i}{\gamma-1}\right)$ is non-negative $(\gamma>1)$, although always with finite values. The second term is also unbounded, its sign depending on $a$ and $b$. Nevertheless, since both are multiplied by $z_{t}^{i}$ it reduces substantially the range of the function. Fig 5.1 presents the effects from changes in $a$ and $b$ over $\frac{\partial y^{\prime}}{\partial y}$. As we can see, if $a>09$, the function will be lower than one ${ }^{10}$ when $i$ approaches one. This means that a redistribution is going

'The same happens for $b<0$.

: Obviously this depends on the magnitude of $b$. 
on, since the individuals' income in the upper deciles of the distribution will grow less than national income. This situation will induce agents in the upper section of the distribution to invest less and agents in the lower regions to invest more, redistributing income for the next periods.

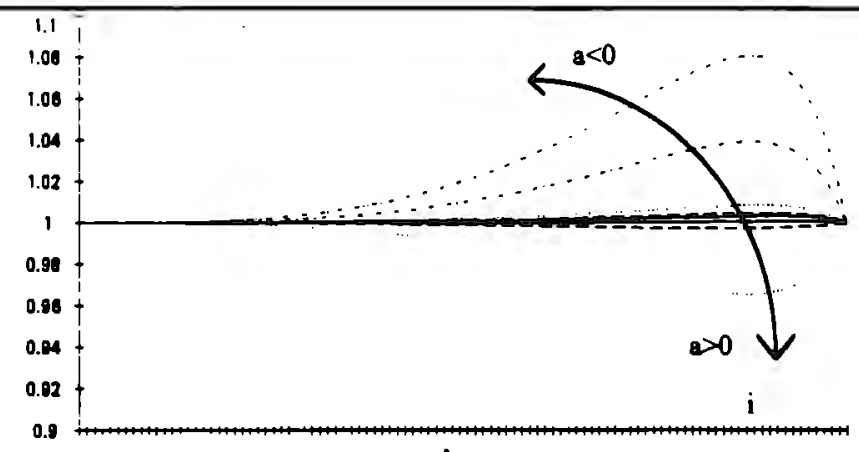

a)

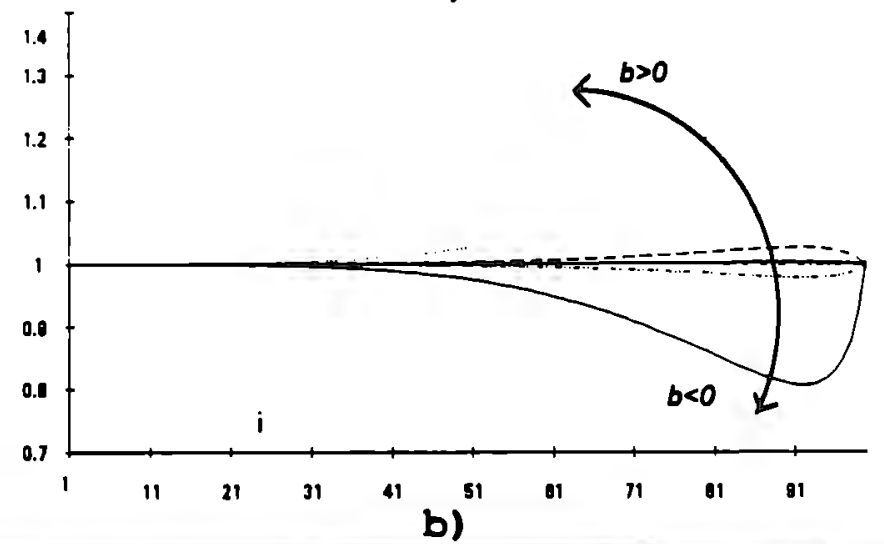

Figure 5.1. Response of $\frac{\partial y^{i}}{\partial y}$ to $a$ and $b$.

Nevertheless, when $a<0$ or $b>0$, the results are the opposite. Individuals at the upper deciles will perceive the marginal utility of their capital to be greater than 
their income, since the effect of national income over their particular income is greater than one, inducing them so invest more, and finally to increase their consumption cver time. This is the force behind the effect of income distribution on economic growth. Income distribution distorts the perceptions of individuals about the marginal productivity of their investment, creating a mechanism that awards capital accumulation for the rich and present consumption for the poor. Nevertheless, $a$ and $b$ are structural parameters. Once they are fixed, different distributions will distort perceptions differently. Fig: 5.2 presents this case: As the Gini coefficient grows, that is, as inequality increases, the number of individuals that perceive their capital "better" is lower. We can see that not only the curve reduces its "height", but also skews to the right.

However, the final effect on growth is determined by (5.22). For the standard case in growth theory which assumes implicitly a completely egalitarian income distribution, the rate is defined by the technical progress and the elasticity of output with respect to capital, that is, $1-\theta$. We can define now the rate of growth for every consumer, and obtain the average growth of the country. Nevertheless, we cannot use the mean 
growth rate, since from our definitions, this mean rate will always be equal to the margina- productivity, since iz is defined as

$$
\bar{g}=\int_{0}^{1} \frac{\dot{c}_{1}}{c_{1}} d i
$$

which will always be equal to the case of a completely egalitarian distribution, because what some individuals gain, some others lose. A measure that would be more appropriate is the median growth, where we obtain the median individual by solving ${ }^{11}$

$$
z_{i}^{i_{+}}+A k^{\theta} \frac{\partial z_{i}^{i_{\infty}}}{\partial y}=1 / 2
$$

for $i$ and substituting it in (5.22). The important point here is, how does income distribution affect growth? Substitute $(5.24)$ in (5.14) to obtain

$$
\rho+\sigma \chi^{i}=A \theta k_{t}^{\theta-1}\left[1 / 2\left(\frac{\alpha}{i}-\frac{\beta}{\gamma-i}\right) d i+z_{t}^{i} d i(a / i-b / \gamma-i)\right]
$$

: See the appendix for details. 
Ne must remember that this equation is evaluated at the median $i_{m}$. Let us start by describing the characteristics $c=i_{m}$.

Proposition 5.1.If a) $z_{1}^{\prime} \geq z_{2}^{\prime} \forall i$, and b) $\frac{\partial z_{1}^{\prime}}{\partial y}=\frac{\partial z_{2}^{\prime}}{\partial y}$, then $i_{m}^{1}<i_{m}^{2}$

Proof: From (5.22), $z_{1}^{1}+\frac{\partial z_{1}^{\prime}}{\partial y}=1 / 2=z_{2}^{\prime}+\frac{\partial z_{2}^{\prime}}{\partial y}$, and using b), $z_{1}^{\prime}=z_{2}^{1}$. Now, from the fact that $z_{1}^{\prime} \geq z_{2}^{\prime} \forall i$, and that they are monotonically increasing functions on $i, i_{m}^{1}<i_{m}^{2}$.

Moreover, when the two distribution intersect, we still can find if the median individual will be closer to one or not, by using

$$
\frac{\partial i}{\partial \alpha}=\frac{\ln i\left(1+\alpha_{y}^{\prime} \ln i\right)}{\frac{\alpha_{y}^{\prime}}{i}+\left(\frac{\alpha}{i}-\frac{\beta}{\gamma-i}\right)\left(1+\alpha_{y}^{\prime} \ln i\right)}
$$

or the equivalent expression for $\beta$,

$$
\frac{\partial i}{\partial \beta}=\frac{\ln \frac{\gamma-i}{\gamma-1}\left(1+\alpha_{y}^{\prime} \ln i\right)}{\frac{\alpha_{y}^{\prime}}{i}+\left(\frac{\alpha}{i}-\frac{\beta}{\gamma-i}\right)\left(1+\alpha_{y}^{\prime} \ln i\right)}
$$


Following the same argument, we can find an expression Eat relates directly the growth rate and the parameters $o=$ the income distribution. In the case of $\alpha$,

$$
\frac{\hat{c} \chi}{\hat{c} \alpha}=A \theta k_{t}^{\theta-1} z_{i}^{i}\left[\left(\ln i\left(\frac{\alpha}{i}-\frac{\beta}{\gamma-i}\right)+\frac{1}{i}\right)\left(1+a \ln i+b \ln \frac{\gamma-i}{\gamma-1}\right)+\ln i\left(\frac{\alpha}{i}-\frac{\beta}{\gamma-i}\right)\right]
$$

and $\beta$,

$$
\frac{\partial \chi^{\prime}}{\partial \beta}=A \theta k_{t}^{\theta-1} z_{i}^{\prime}\left[\left(\ln \frac{\gamma-i}{\gamma-1}\left(\frac{\alpha}{i}-\frac{\beta}{\gamma-i}\right)+\frac{\gamma-1}{\gamma-i}\right)\left(1+a \ln i+b \ln \frac{\gamma-i}{\gamma-1}\right)+\ln \frac{\gamma-i}{\gamma-1}\left(\frac{\alpha}{i}-\frac{\beta}{\gamma-i}\right)\right]
$$

These two functions are very complex. In general, (5.28) will be non-positive and (5.29) non-negative. Unfortunately, it is not possible to get a stronger result, since the values and signs of $a$ and $b$ are unknown. We have shown in proposition 5.1 that in the case that $\alpha$ and $\beta$ move towards more egalitarian distributions, the median individual will move down to zero, meaning that more people grow above the median. However, the final effect on growth is much more difficult to find. It seems 
From the equations presented above that, in general, more egalitarian distribution will lead to faster growth, but inis is not always the case.

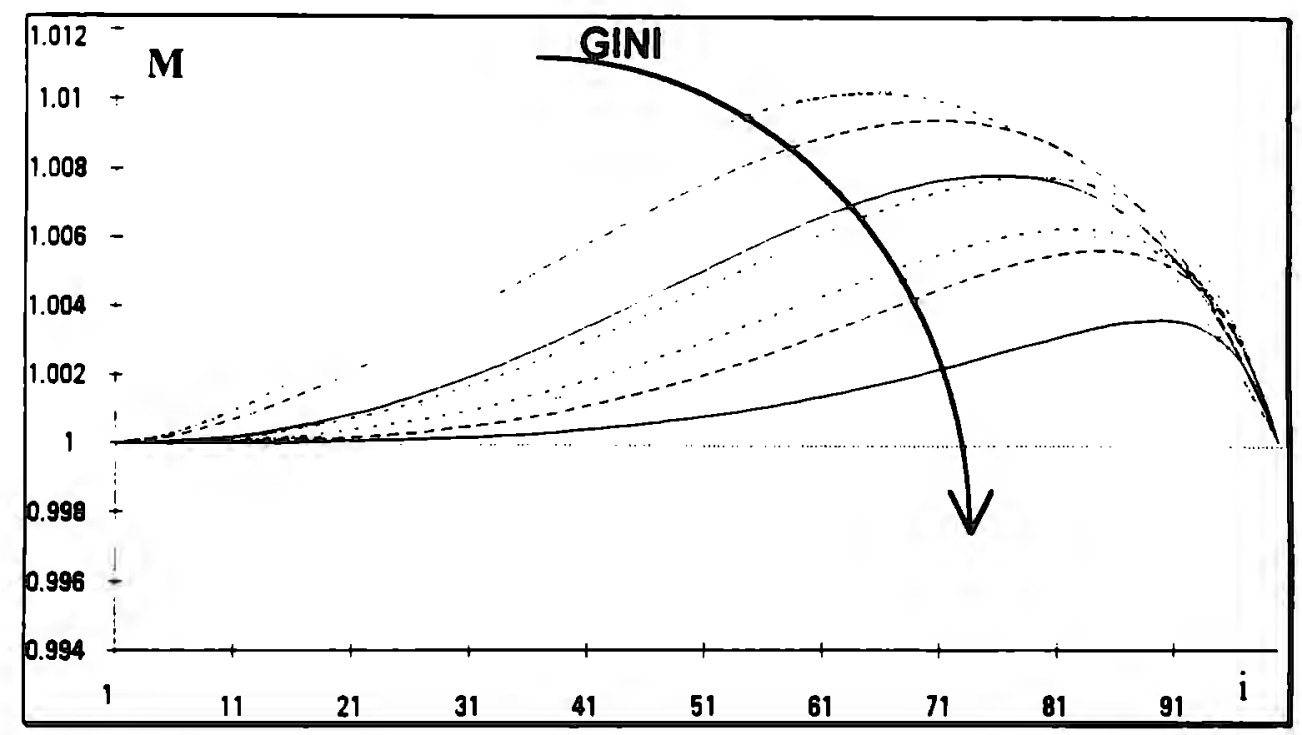

Figure 5.2. $\mathbf{M}_{\text {t }}$ and Gini coefficient

More than that, it is possible that for two different countries with curves having the same Gini coefficient, that is, the same "inequality", one grows faster than the other. Figures 5.3 and 5.4 show this case. In figure 5.3 , L2 and L1 have the same area under them, that is, the same Gini coefficient. Nevertheless, a country having L2 would grow faster than one having L1. One would have the temptation to say that it happens because L2, although having the same Gini coefficient, has bigge: income for the poor. That is not true in general. 


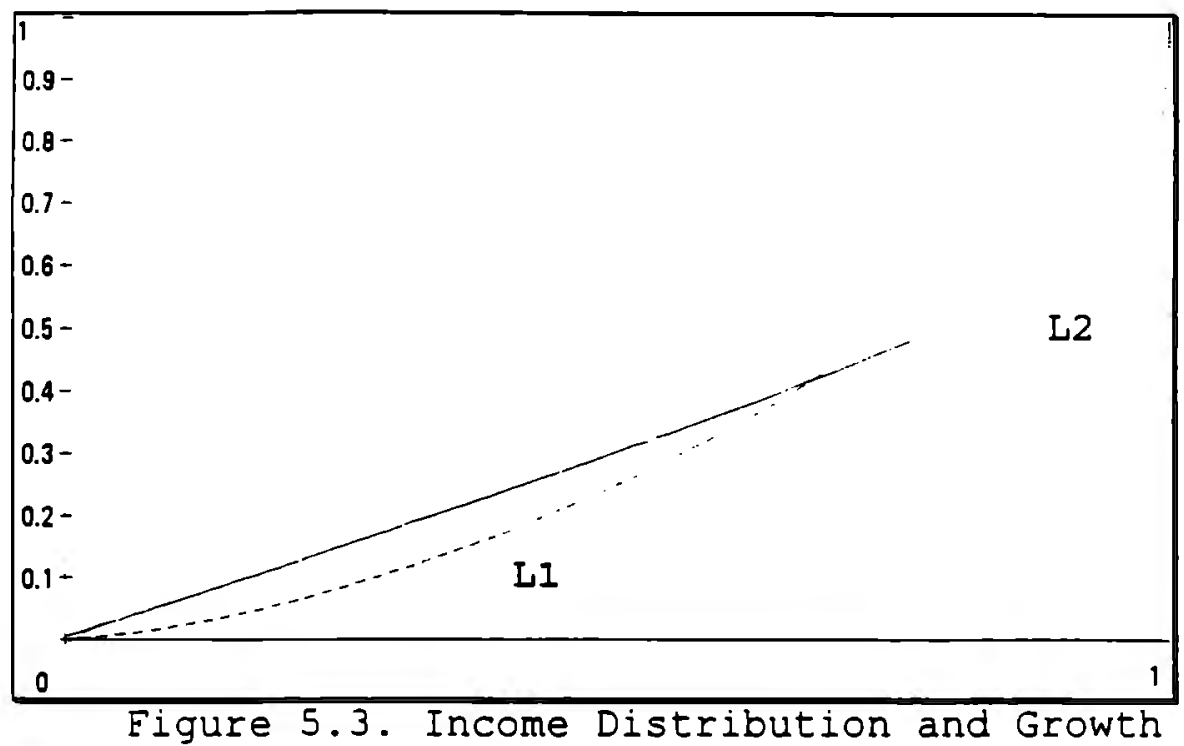

Eigure 5.4 presents the opposite case. Now, the country having $\mathrm{Ll}$ as the Lorenz curve will grow faster than a country with L2. And now the poor people receive less income in L1 than in L2. These two figures illustrate that it is not a general result when the Lorenz curves intersect.

Using equations (5.26) and (5.27) we could have information about the change in growth whenever income distribution changes. But we cannot have a general statement about distribution and growth. Nevertheless, numerical solution to the model shows that, in general, more egalitarian distribution means faster growth. 
However, when the two curves cover similar areas the results are ambiguous.

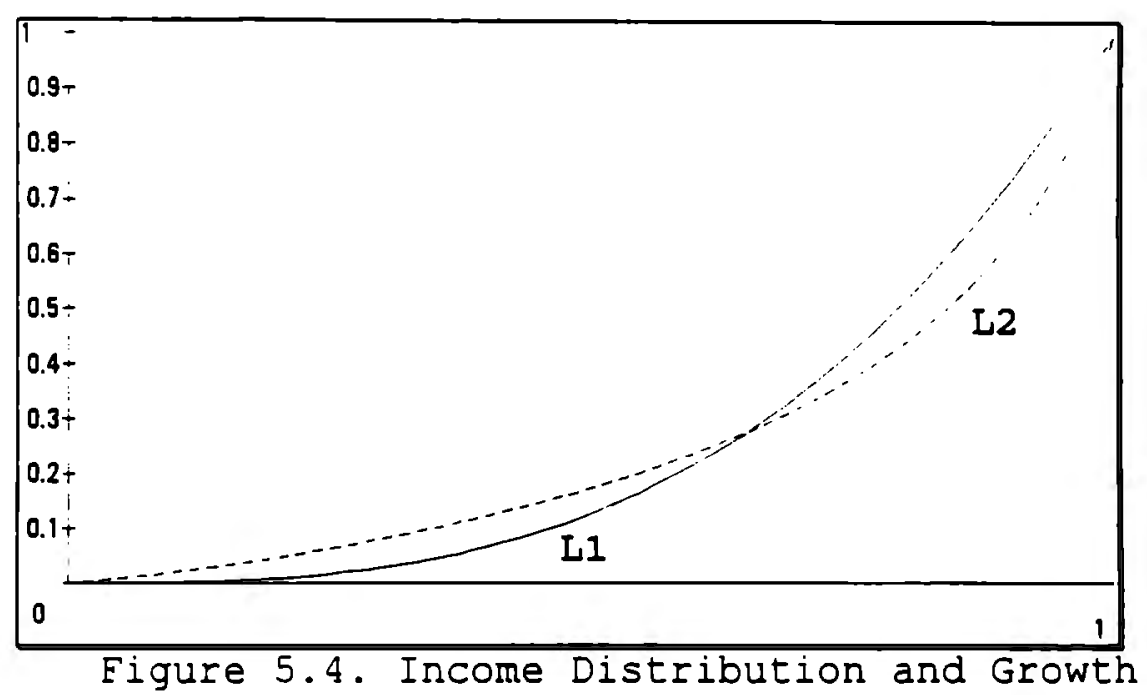

A final remark on this model is that, opposite to the one presented in chapter 3 ... where non-egalitarian distribution affects growth through the political equilibrium, in the model stated here, the effect of income distribution is through returns on investment. Since individuals have different returns depending on ? their positions in the distribution, they will be more or less willing to postpone consumption, and this will determine the country's present and future consumption, that is, the country's economic growth. 
III. Empirical results

In order to have some idea about the values and signs of $a$ and $b$, I made a couple of empirical explcratory studies. One of them using data from 28 countries:Income distribution data from the world Bank (1984) and national income from Summers and Heston's Mark 5 database (1991). The parameters $\alpha, \beta$ and $\gamma$ appear in Table 5.7. Note that $\gamma$ was estimated for every country and it is very stable. Results from this cross country study appear in Table 5.1. Also Eig. 5.5 and 5.6 present $\alpha$ and $\beta$ in relation to RGNP. Note that correlations are not very high. This was to be expected, since income distribution includes much more-than income, capital accumulation, etc.

The other exploratory study was done with income distribution data for Mexico. The problem here is that with only seven data points, it is very difficult to find statistical significance for the relation between income distribution and national income. Nevertheless, since income distribution in 1984 is clearly more egalitarian than in 1977 or 1989, we could use proposition 5.1 to state that the possibilities of growth in 1984 were better

: icf. previous chapter 
than in the other two years we have data. This would seem Ealse at first sight, since Mexico didn't grow from 1984 $=0.1989$ (less than 1.5 GNP growth per year). On the contrary, what happened on those years was a very high growth rate of the informal economy (Schettino, 1992), reaching more than $20 \%$ of the GNP in the five year period, far greater than from 1989 to 1992.

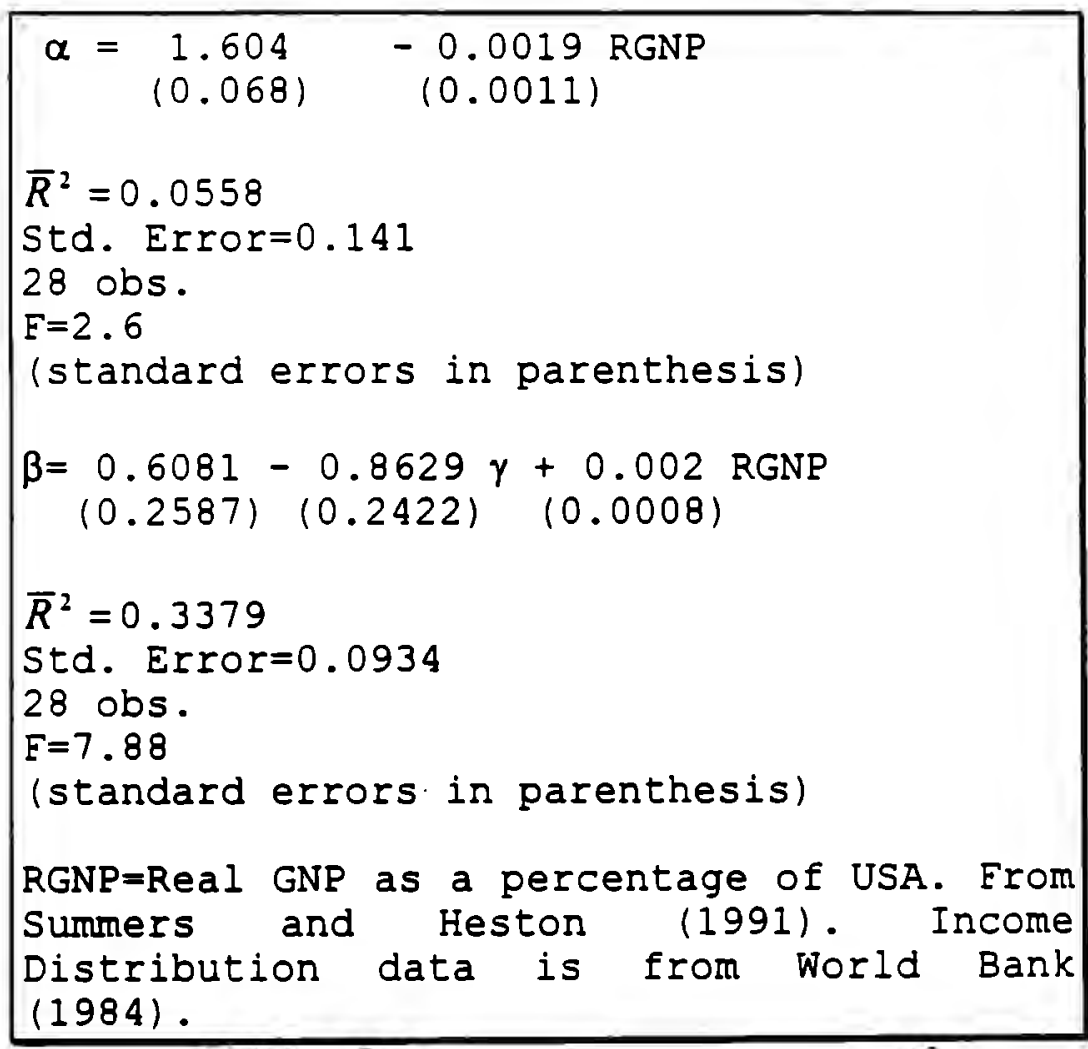

Table 5.1. Cross Country results 


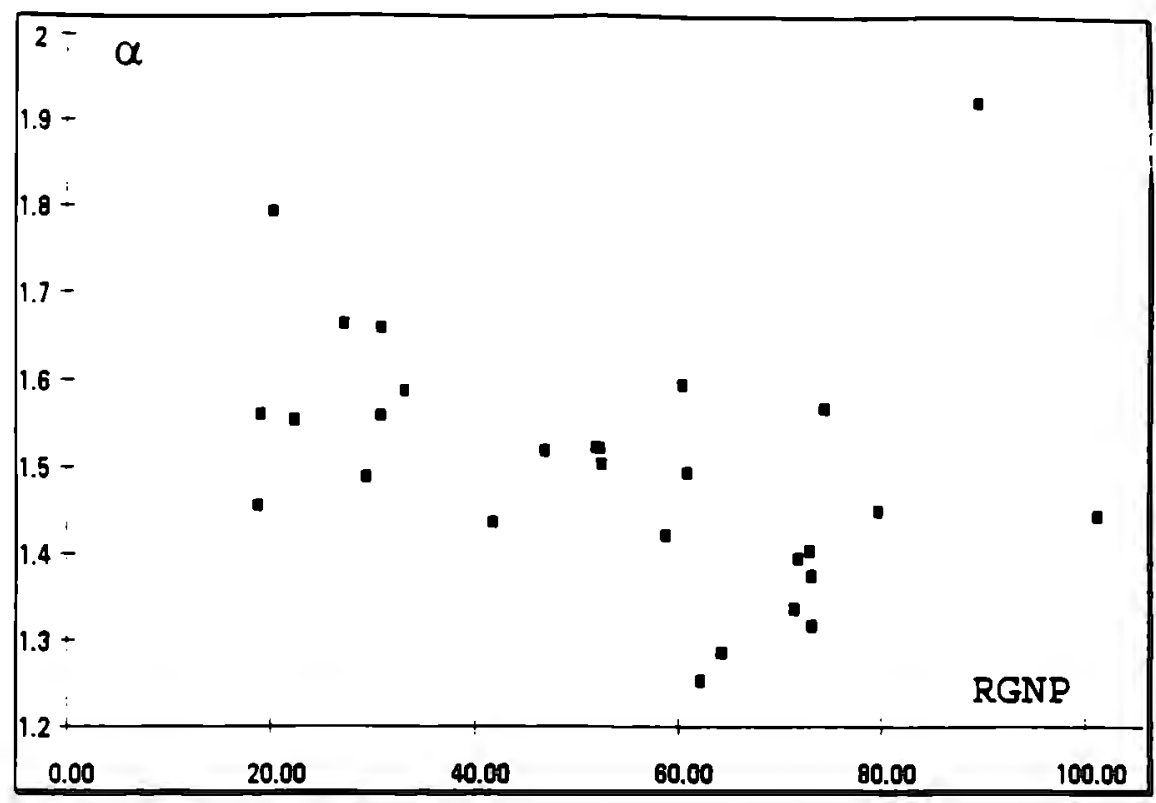

Figure 5.5. Income and Distribution. Parameter $\alpha$

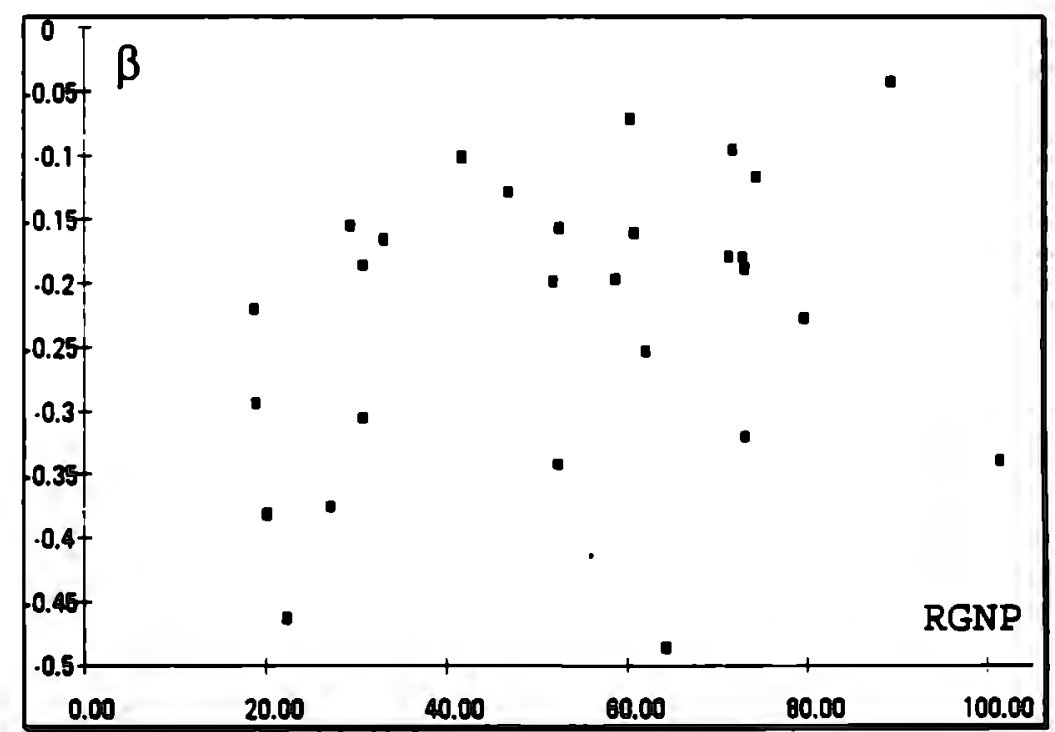

Figure 5.6. Income and Distribution. Parameter $\beta$ 


\section{APPENDIX TO CHAPTER 5}

The derivative of individuals income with respect to national income is

$$
\begin{aligned}
\frac{\partial y_{t}^{\prime}}{\partial y_{t}} & =\frac{\partial\left(z_{t}^{\prime} A k_{t}^{\theta}\left(\frac{\alpha}{i}-\frac{\beta}{\gamma-i}\right) \Delta i\right)}{\partial y_{t}} \\
& =\frac{\partial z_{t}^{\prime}}{\partial y_{t}} A k_{t}^{\theta}\left(\frac{\alpha}{i}-\frac{\beta}{\gamma-i}\right) \Delta i+z_{t}^{i} \frac{\partial\left(\frac{\alpha}{i}-\frac{\beta}{\gamma-i}\right)}{\partial y_{t}} A k_{t}^{\theta} \Delta i \\
& =z_{t}^{\prime}\left(a \ln i+b \ln \frac{\gamma-i}{\gamma-1}\right)\left(\frac{\alpha}{i}-\frac{\beta}{\gamma-i}\right) \Delta i+z_{t}^{i}\left(\frac{a}{i}-\frac{b}{\gamma-i}\right) \Delta i
\end{aligned}
$$

where we have used the definitions of $a$ and $b$ from (5.13). Multiply the last equation by $A \theta k_{t}^{\theta-1}$ to get equation (5.15).

In order to find the median individual, the following equation must hold:

$$
\int_{0}^{I_{m}} A \theta k_{t}^{\theta-1}\left[\frac{\partial z_{t}^{i}}{\partial i}+A k^{\theta} \frac{\partial^{2} z_{t}^{i}}{\partial i \partial y}\right] \Delta j=\int_{i_{-}}^{1} A \theta k_{t}^{\theta-1}\left[\frac{\partial z_{t}^{i}}{\partial i}+A k^{\theta} \frac{\partial^{2} z_{t}^{i}}{\partial i \partial y}\right] \Delta i
$$


we can eliminate $A \theta \boldsymbol{k}_{l}^{\theta-1}$ from both sides ana get

$$
\int_{0}^{I_{m}} \frac{\partial z_{t}^{1}}{\partial i} \Delta i+A k^{\theta} \int_{0}^{I_{m}} \frac{\partial^{2} z_{l}^{1}}{\partial i \partial \partial} \Delta i=\int_{I_{m}}^{1} \frac{\partial z_{t}^{1}}{\partial i} \Delta i+A k^{\theta} \int_{I_{m}}^{1} \frac{\partial^{2} z_{l}^{1}}{\partial i \partial y} \Delta i
$$

Integrating, and making use of the fact that $z(1)=1$, and $\frac{\hat{c} z_{1}^{\prime}}{\hat{c} y}(1)=z(0)=0$, we get

$$
\begin{aligned}
& \left.z_{i}^{1}\right|_{0} ^{l_{m}}+\left.A k^{\theta} \frac{\partial z_{t}^{1}}{\partial y}\right|_{0} ^{l_{m}}=\left.z_{t}^{i}\right|_{l_{m}} ^{1}+\left.A k^{\theta} \frac{\partial z_{t}^{i}}{\partial y}\right|_{l_{m}} ^{1} \\
& z_{t}^{i_{+}}+A k^{\theta} \frac{\partial z_{t}^{i_{m}}}{\partial y}=1-z_{t}^{i_{+}}+A k^{\theta}\left(0-\frac{\partial z_{t}^{i_{+}}}{\partial y}\right) \\
& z_{t}^{i_{m}}+A k^{\theta} \frac{\partial z_{t}^{i_{m}}}{\partial y}=1 / 2
\end{aligned}
$$

which corresponds to equation (5.22). 
CHAPTER 6

ENDOGENOUS GROWTH AND INCOME DISTRIBUTION

In order to have a better idea of the way income distribution affects growth, I also develop a model of endogenous economic growth, following the idea of Lucas $k$ (1988) of the synergy of human capital. As in the simpler model, individuals are indexed by $i=0 . .1$, and maximize an intertemporal utility function like (5.1), subject to their budget constraint (5.2), where national income is now defined as

$$
Y_{t}=A k_{t}^{\theta}\left(u_{t}^{i} h_{t}^{i}\right)^{1-\theta} h_{a}^{\mu}
$$

where, following Lucas, we incorporate human capital as a production factor with two effects: one, which is properly acknowledged by the firm, is the normal way in which labor enters a production function; the other is the effect that the accumulation of human capital has for the firm. Nevertheless, this last effect, also called the external effect, is not recognized by the firm or by the workers. It represents the increasing returns that allow long-run endogenous growth. 
Human capital is accumulated, also following Lucas, through

$$
\dot{h}_{t}^{\prime}=z_{t}^{\prime} \eta\left(1-u_{t}^{\prime}\right) h_{t}^{\prime}
$$

where $\eta$ represents the efficiency in this accumulation, although income distribution also affects this part. The current-value Hamiltonian will now be

$$
H\left(\boldsymbol{k}^{\prime}, \boldsymbol{h}^{\prime}, \lambda_{1}, \lambda_{2}, c^{t}, \boldsymbol{u}^{\prime}, t\right)=U\left(c_{t}^{i}\right)+\lambda_{1} \dot{k}_{t}^{i}+\lambda_{2} \dot{h}_{t}^{i}
$$

The first order conditions will be

$$
\begin{aligned}
& U_{c}^{\prime}=\lambda_{1} \\
& \lambda_{1} z_{t}^{i} A\left(\frac{\alpha}{i}-\frac{\beta}{\gamma-i}\right) k_{t}^{\theta}\left(u_{t}^{i} h_{t}^{i}\right)^{1-\theta} h_{a}^{\mu}\left(\frac{1-\theta}{u_{t}^{\prime}}\right)=\lambda_{2} z_{t}^{i} \eta h_{t}^{i}
\end{aligned}
$$

and the co-state motion equations are now

$$
\frac{\dot{\lambda}_{1}}{\lambda_{1}}=\rho-A \theta z_{t}^{i}\left(\frac{\alpha}{i}-\frac{\beta}{\gamma-i}\right) \Delta i k_{t}^{\theta-1}\left(u_{t}^{i} h_{t}^{i}\right)^{1-\theta} h_{a}^{\mu} \mathbf{M}_{t}^{i}
$$

and

$$
\frac{\dot{\lambda}_{2}}{\lambda_{2}}=\rho-\frac{\lambda_{1}}{\lambda_{2}} A z_{1}^{i}\left(\frac{\alpha}{i}-\frac{\beta}{\gamma-i}\right) \Delta i k_{t}^{\theta}\left(u_{t}^{i} h_{t}^{i}\right)^{1-\theta} h_{a}^{\mu}\left(\frac{1-\theta}{h_{t}^{i}}+\frac{\mu}{h_{a}}\right)-z_{t}^{\prime} \eta\left(1-u_{t}^{i}\right) \quad \text { (6.6) }
$$


Eollowing the same procedures as in the case of the simpler model, we get to

$$
A \theta z_{t}^{\prime}\left(\frac{\alpha}{i}-\frac{\beta}{\gamma-i}\right) \Delta i k_{t}^{\theta-1}\left(u_{t}^{\prime} h_{t}^{\prime}\right)^{1-\theta} h_{a}^{\mu} \mathbf{M}_{t}^{\prime}=\rho+\sigma \chi_{t}^{\prime}
$$

where

$$
\mathbf{M}_{t}^{\prime}=1+a \ln i+b \ln \frac{\gamma-i}{\gamma-1}+\frac{a / i-b /(\gamma-i)}{\alpha / i-\beta /(\gamma-i)}
$$

and

$$
a=A k_{t}^{\theta} \alpha_{y}^{\prime} \quad \text { and } \quad b=A k_{t}^{\theta} \beta_{y}^{\prime}
$$

which is the equivalent to (5.19) and behaves exactly as in the simpler model. Also in this case individuals. perceive the marginal productivity of their capital as different from the real one, and the difference is (6.8). Note that the conclusions for the one-good model are still valid here, namely, agents perceive the returns to their investments differently and have, then, more or less propensity to save. We can also obtain a function for $\chi^{i}$ here, 


$$
\chi^{\prime}=\sigma^{-1}\left[z_{t}^{\prime} \mathbf{M}_{t}^{\prime}\left(\frac{\alpha}{i}-\frac{\beta}{\gamma-i}\right) \Delta i(\rho+\sigma \chi)-\rho\right]
$$

which is quite similar to the one obtained in chapter 5 . Moreover, proposition 5.1 is still valid, singe $z_{L}^{\prime} \mathbf{M}_{L}^{\prime}$ is $\therefore$ ractically the same function. From (6.4) and (6.6), we get

$$
\frac{\dot{\lambda}_{2}}{\lambda_{2}}=\rho-z_{1}^{\prime} \eta\left(\frac{1-\theta+\mu}{1-\theta}\right)+v\left(\frac{\mu}{1-\theta}\right)
$$

where $v=\dot{h} / h$. Here we are assuming that the external. effect of human capital can be decided, that is, in the efficient path as Lucas calls it. On the other hand, if we suppose that this effect is given, as will be for the individuals, $(6.10)$ becomes

$$
\frac{\dot{\lambda}_{2}}{\lambda_{2}}=p-z_{1}^{i} \eta
$$

the equilibrium path. Now, if we differentiate (6.4), we obtain

$$
\frac{\dot{\lambda}_{2}}{\vdots}=-\sigma \chi^{i}+\theta x+(\mu-\theta) v
$$


Differentiating (6.7), we can find an equation for the $c E=-\pi$ l rate of growth of capital, equivalent to (5.15) in the simpler model. This equation, evaluated for $i=1$, is

$$
\chi=\frac{1-\theta+\mu}{1-\theta} v
$$

and, if we equate $(6.11)$ and $(6.12)$ and substitute (6.13), we find the optimal rate of growth of human capital, always for the case $i=1$,

$$
v^{*}=\sigma^{-1}\left[\eta-\frac{1-\theta}{1-\theta+\mu} \rho\right]
$$

Nevertheless, the effect of income distribution also appears in this model, and what we have is:

$$
v_{i}^{*}=\frac{\rho-\left(\frac{1-\theta+\mu}{1-\theta}\right) z_{i}^{i} \eta+\sigma \chi^{i}-\theta \chi}{\mu-\theta-\frac{\mu}{1-\theta}}
$$

and, applying the same operations to the equilibrium path, we obtain

$$
v_{1}=\frac{\rho-z_{i}^{i} \eta+\sigma \chi^{i}-\theta \chi}{\mu-\theta}
$$


Note that (6.15) and (6.16) give the technical progress Eor each individual, that is, we have... differentiated technological progress. To further analyze these equations, substitute (6.13) in both of them to get

$$
\begin{gathered}
v_{1}^{*}=\frac{1}{\theta^{2}}\left[\left(\frac{1-\theta}{1-\theta+\mu}\right) \rho-z_{i}^{\prime} \eta+\sigma \chi^{\prime}\right] \\
v_{1}=\frac{\rho-z_{t}^{\prime} \eta+\sigma \chi^{i}}{\mu}
\end{gathered}
$$

now substitute $(6.9)$ in both of them to find

$$
\begin{aligned}
& v_{i}^{*}=\frac{\left(\frac{-\mu}{1-\theta+\mu}+z_{t}^{i} \mathbf{M}_{t}^{i}\left(\frac{\alpha}{i}-\frac{\beta}{\gamma-i}\right) \Delta i\right) \rho-z_{t}^{i} \eta}{\theta^{2}-z_{t}^{i} \mathbf{M}_{t}^{i}\left(\frac{\alpha}{i}-\frac{\beta}{\gamma-i}\right) \Delta i \sigma \frac{1-\theta+\mu}{1-\theta}} \\
& v_{i}=\frac{z_{t}^{i} \eta-z_{t}^{i} \mathbf{M}_{t}^{i}\left(\frac{\alpha}{i}-\frac{\beta}{\gamma-i}\right) \Delta i \rho}{\left(z_{t}^{i} M_{i}^{i}\left(\frac{\alpha}{i}-\frac{\beta}{\gamma-i}\right) \Delta i \sigma \frac{1-\theta+\mu}{1-\theta}-\mu\right)}
\end{aligned}
$$

and compare (6.19) with (6.14) and (6.20) with 


$$
v=\frac{(1-\theta)(\eta-\rho)}{\sigma(1-\theta+\mu)-\theta}
$$

which is the equilibrium rate of technical-progress for the uniform income distribution. (6.19) can't be equal to (6.14), even if we assume a totally egalitarian distribution, since the denominator in (6.19) would become $\sigma \frac{1-\theta+\mu}{1-\theta}-\theta^{2}$, where the denominator in (6.14) is just $\sigma$. (6.19) will be smaller than (6.14) whenever $\sigma>\frac{\theta^{2}(1-\theta)}{\mu}$, which is quite similar to the feasibility restriction posed by Lucas (1988). This means that if income distribution is not egalitarian, the efficient growth rate will be lower.

On the other hand the denominator of (6.20) under an egalitarian distribution is $\sigma(1-\theta+\mu)-\mu(1-\theta)$, while for $(6.21)$ it is $\sigma(1-\theta+\mu)-\theta$. The condition that makes $(6.20)$ smaller than $(6.21)$ is $\mu<\frac{\theta}{1-\theta}$, that is, the elasticity of production against the external effect of human capital must be smalier than the ratio of the elasticities of physical and human capitat. This happens, for example, when $\mu=0$, which means that if there is no external effect, 
the same conclusion of the last paragraph holds here: less egalitarian distributions lead to less technical progress.

We have shown that in the endogenous growth model, growth is reduced by non-egalitarian income distributions in two ways. First, as in the case of the one-good model, the distortions that a non-egalitarian income distribution produces on the agents move the poor to save less and the rich to save more than what would be optimal, leading the country to grow less, on average, than it would under an egalitarian distribution. The second effect will be that a non-egalitarian income distribution reduces the rate of technical progress under an endogenous growth model. This would increase the difference between two countries with diverse income distributions.

A final point to be made is that we have assumed that income distribution affects the efficiency of human capital accumulation. The conclusions of the model seem to reinforce the issue we talked about in the preceding chapter. "Conventional wisdom" says that poor people are still poor because they don't save and don't study. This model shows that this "wisdom" is true in the conclusion, but it needs another interpretation: Income distribution distorts economic signals in such a way that reduces 
incentives of the poor to invest or "study", leading them to stay poor. The agents with more income will, on the other hand, invest and "study" more than what would be optimal, directing them to stay rich.

Another important point is that the external effect of Lucas maybe affected by income distribution the same way that physical capital is. Not only the level of human $M$ capital would determine this external effect but also the distribution of human capital may have very much to do with the externalities in production. For example, imagine a modified Lorenz curve that maps individuals not to income but to human capital. As in figures 5.3 and 5.4, where we have the same Gini coefficient for two very different income distributions, we may have the same aggregate amount of human capital but with very different distributions. For example, take the case of one country with a non-egalitarian distribution of human capital, that is, several Ph.D. and some engineers, but the rest of the people illiterate, as is the case of most Latin American countries (which have very non-egalitarian income distributions as well); on the other hand, take another country with the same aggregate human capital but composed of many high-skilled workers, although with few Ph.D. or 
none at all, as was the case of southeast Asian countries arolind the fifties. The external effect, that is the sinergy that can be obtained in the latter would be far greater than in the former case. How does a Ph.D. manage to work with an almost illiterate worker? Is there any possibility of having an external effect? If there is, it will certainly be lower than when two skilled workers join production.

Although we have not reached to this point, it seems natural to follow up this kind of models that analyze growth and distribution at the same time, in order to grab the complex issues related to economic growth from a more realistic perspective. 
CHAPTER 7

CONCLUSIONS

This dissertation had two main objectives. One is already in its title, to find some more about the relation between income distribution and economic growth. The other was a personal view: show that Development Economics may have a lot to explain, and it can do it in formal terms. It is clear to me that good ideas can be stated by anyone, but without the proper presentatic:., they may not be good enough. In the first chapter I have developed this point a little.

Regarding the first, and most important, objective, chapters 3 to 6 present different approaches to the same issue. Starting from a model by Persson and Tabellini (1991), chapter 3 presents some preliminary results of including political feasibility in a model of distribution and growth. The conclusions from this chapter are striking in the sense that there may be some distributions that are incompatible with political peace.

In order to find a more formal and overwhelming way to analyze income distribution and economic growth, chapter 4 
develops a function that fits the Lorenz curve and has interesting properties: First, from an empirical viewpoint, this function fits the actual curve with only three parameters and the values of these are quite stable even if we have a small sample; second, the functional form is quite easy to incorporate in more complex models and the parameters seem to have intuitive explanations related to other economic variables.

We have constructed a model of economic growth in chapter 5 including a function of income distribution that responds to changes in income. The solution of this model presents some interesting insights on the economic development process. Once we have found the way in which income distribution depends on the economic variables, we can describe the process that growth will follow. We can also show that, in general, the less egalitarian the distribution, the lower the median rate of growth.

In chapter 6, the model is enhanced to include endogenous forces in the growth process. Conclusions are somewhat stronger than in chapter 5, since we are able to extend the results to human capital accumulation. 
A final remark on the distributional issue may be important. Income distribution includes much more than income, capital accumulation, etc. In fact it incorporates the effect of institutions,.. culture, demographics, and everything we normally leave out of the models. One of the important points of using this income distribution function in the growth model is that we are modeling reality quite closely and this allows us to find the relationship of income distribution and growth not through a political equilibrium, but through the different returns on investment that individuals have. Since individuals have different returns depending on their positions in the distribution, they will be more or less willing to postpone consumption, and this will determine the country's present and future consumption; that is, the country's economic growth.

Further research on the development process should include, then, a) studying the mechanisms that determine the values of the parameters; b) to incorporate more complex endogenous technical progress, including the effect of human capital distribution; c) to incorporate richer population and economic characteristics in the model; d) to incorporate political equilibrium; and, 
finally, e) to do much more empirical research in all of these directions. 


\section{BIBLIOGRAPHY}

Abramovitz, M. Thinking about Growth, Cambridge University Press, 1991.

Adams, J.D. "Fundamental Stocks of Knowledge and Productivity Growth", Journal of Political Economy $1990,98(4)$.

Adelman, I. and Taylor, J.E. "Changing Comparative Advantage in Food and Agriculture: Lessons from Mexico", Development Centre of the OECD, Paris, 1990.

Aitchinson, J. and J.A.C. Brown, The lognormal distribution, Cambridge University Press, Cambridge, 1957.

Alesina, A. and Rodrik, D. "Distributive Politics and Economic Growth", NBER working paper 3668, NBER March 1991.

Amos, O.M.Jr. "Unbalanced Regional Growth and Regional Income Inequality in the Latter stages of Developmnet", Regional Science and Urban Economics $18(1988)$.

Arrow, K.H. "The Economic Implications of Learning by Doing", Review of Economic studies XXIX(3), no. 80 , June 1962

Arts, W., Hermkens, P. and van Wijck, P. "Income and the Idea of Justice: Principles, Judgments and their Framing", Journal of Econ. Psych. 12(1) march 1991, pp. 121-140.

Asimakopoulos, A. (ed.) Theories of Income Distribution, Kluwer, Boston, 1987

Atkinson, A.B. The Economics of Inequality, Clarendon Press, Oxford, 1975. 
Atoda, N. and Tachibanaki, T. "Earnings Distribution and Inequality over Time: Education versus Relative Position and Cohort", International Economic Review, 32(2) May 1991.

Baghwati, J.N., "Immiserizing Growth: A Geometrical Note" Review of Economic Studies, 25, 201-205.

Barro, R.J. "A Cross-Country study of Growth, Saving and Government", NBER working paper 2855, NBER Feb 1989

Barro, R.J. "Government spending in a Simple Model of Endogenous Growth", Journal of Political Economy $1990,98(5)$.

Barro, R.J. "Economic Growth in a Cross section of Countries", Quarterly Journal of Economics, $106(2)$, May 1991

Barro, R.J. and Sala-i-Martin, X. "Public Finance in Models of Economic Growth", NBER working paper 3362, NBER MaY 1990

Bartels, C.P.A. Economic Aspects of Regional Welfare, Income Distribution and Unempolyment, Martinus Nihoff, Leiden 1977.

Basmann, R.L., Hayes, K.J., Slottje, D.J. and Johnson, J.D., "A General Functional Form for approximating the Lorenz Curve", Journal of Econometrics 43, 1990, pp. 77-90.

Basmann, R.L., Hayes, K.J., Slottje, D.J., "The Lorenz curve and the Mobility Function", Economic Letters 35, 1991, pp. 105-111.

Becker, G.S. "Noble Lecture: The Economic Way of Looking at Behavior", Journal of Political Economy, 101(3) June 1993, pp. 385-409

Becker, G.S., Murphy, K.M. and Tamura, R. "Human Capital, Eertility and Economic Growth", Journal of Political Economy 1990, 98 (5). 
Bourguignon, F. and Morrison, C. "Income Distribution, Development and Foreign Trade", European Economic Review 34 (1990).

Bowen, H.P. and Sveikauskas, L. "Judging Factor Abundance", Quarterly Journal of Economics,

Bowles, R. and Jones, P. "Political Participation and the Limits to Redistribution", European Journal of Poli- zal Economy 7 (1991)

Buffie, E.F. "Commercial Policy, Growth and the Distribution of Income in a Dynamic Trade Model", Journal of Dev. Econ. 37 (1992)

Champernowne, D.G. [1953], "A Model of Income Distribution", Economic Journal 63, pp. 318-351

Chang, W.W. and Chiang, S.-H. "A Model of Growth and Trade in Time-Phased Economies", International Economic Rev., 27(3), Oct, 1986.

Chari, V.V. and Hopenhayn, H. "Vintage Human Capital, Growth and the Diffusion of new Technology", Journal of Political Economy, 1991, 99(6).

Chenery, H.,Ahluwalia, M.S., Bell, C.L.G., Duloy, J.H., Jolly, R. Redistribution with Growth, World Bank and Institute of Development Studies, Oxford University Press, 1974.

Cutler, D.M. and Katz, L.F. "Macroeconomic Performance and the Disadvantaged" (Comments and Discussion), Brookings Papers on Economic Activity, 1991 issue 2 pp. 1-74.

Dasgupta, A.K. Growth, Development and Welfare, Basil Blackwell, 1988.

Dasgupta, P. "Nutrition, Non-convexities and Redistributive Policies", in Hey, J.D. op. cit. 1992 .

Dixit, A.K. The Theory of Equilibrium Growth, Oxford University Press, 1976. 
Dowrick, S. "Technological Catch jp and Diverging Incomes: Patterns of Economic Growth 1960-88", The Economic Journal, 102, May 1992

Dowrick, S. and Gemmell, N. "Industrialisation, Catching Up and Economic Growth: A Comparative Study across the World's Capitalist Economies", The Economic Journal, 101 (March 1991).

Dreze, J. and Sen, A. Hunger and Public Action, Clarendon Press, Oxford, 1989.

Eatwell, J., Milgate, M. and Newman, P. (eds.) The New Palgrave: A Dictionary of Economics, MacMillan, Hong Kong, 1987 (Entries: Human Capital, Growth and International Trade, International Trade, Income Distribution).

Ehrlich I, and Lui, F.T. "Intergenerational Trade, Longevity and Economic Growth", Journal of Political Economy, 1991, 99(5).

Esfahani, H.S. "Exports, Imports and Economic Growth in semi-industrialized countries", Journal of Dev. Econ. 35 (1991)

Fields, G.S. "Measuring Inequality Change in an Economy with Income Growth", Journal of Dev. Econ. 32 (1) Jan 1990

Findlay, R. and Wilson, J.D. "The Political Economy of Leviathan", in Razin, a. and Sadka, E. (eds.) Economic Policy in Theory and Practice, st. Martin's Press, New York 1987

Flam, H. and Helpman, E. "Vertical Product Differentiation and North-South Trade", American Eeconomic Review $77(5)$.

Flug, $K$. and Galor, $O$. "Minimum Wage in a General Equilibrium Model of International Trade and Human Capital", International Econ. Rev. 27(1), Feb. 1986

Fung, K.M. and Ishikawa, J. "Dynamic Increasing Returns, Technology and Economic Growth in a Small Open Economy", Journal of Dev. Econ. 37 (1992). 
Glomm, G. and Ravikumar, B. "Public versus Private Investment in Human Capital: Endogenous Growth and Income Inequality". Journal of Political Economy, $100(4)$, August 1992, pp. 818-834.

Grossman, G. "Explaining Japan's Innovation and -rade: A Model of Quality Competition and Dynamic comparative Advantage", NBER Working Paper 3194, NBER DeC. 1989

Grossman, G. and Helpman, E. "Product Development and International Trade", Journal of Political Economy $1989,97(6)$.

Grossman, G. and Helpman, E. "Trade, Innovation and Growth", American Economic Review $80(2)$.

Grossman, G. and Helpman, E. Innovation and Growth in the Global Economy, MIT, 1991.

Halperin, A. and Teubal, M. "Government Policy and Capability-creating Resources in Economic Growth", Journal of Dev. Econ. 35 (1991)

Harcourt, G.C. and Laing, N.F. (eds.) "Capital y Crecimiento", Lecturas del Trimestre Económico 18, FCE, México, 1973. Title in English: Capital and Growth, Penguin Books, 1971.

Helpman, E. "Growth, Technical Progress and Trade", NBER working paper 2592, NBER May 1988.

Herrick, B. and Kindleberger, C.P. Economic Development, 4th. ed., McGraw-Hill, 1983.

Hey, J.D.(ed.) The Future of Economics, Blackwell, London, 1992 .

IMSS/COPLAMAR Necesidades Básicas en México, tomo V. 1981.

INEGI Encuesta Ingreso-Gasto de los Hogares, 1984. INEGI/SPP, México, 1987

INEGI Encuesta Ingreso-Gasto de los Hogares, 1989. INEGI/SPP, México, 1991 
Juhn, C., Kurphy, K. and Pierce, B. "Wage Inequality and the rise in Returns to skill", Journal of Political Economy, 101(3), June 1993.

Jung, J.H. "Human capital, Economic Growth, and Income Distribution: Korea and the United States", University of Illinois-Urbana, Dissertation, 1990

Kakwani, N.C. Income Inequality and Poverty. Methods of Estimation and Policy Applications. Oxford University Press for the World Bank, Washington, 1980

Kamien, M.I. and Schwartz, N.L. Dynamic Optimization. The Calculus of Variations and optimal Control in EConomics and Management, 2nd Ed. North Holland, 1991

King, R.G. and Rebelo, S. "Public Policy and Economic Growth: Developing Neoclassical Implications", Journal of Political Economy 1990, 98(5).

Krueger, A.O. "Government Failures in Development", NBER working paper 3340, NBER Apr. 1990

Krueger, A.O. and Orsmond, D. "Impact of Government on Growth and Trade", NBER working paper 3545, Dec. 1990

Kuznets, S. Economic Development, the Family and Income Distribution. Selected Essays, Cambridge University Press, 1989.

Kuznets "Economic Growth and Income Distribution", American Economic Review, 1955

Lucas, R.E. Jr. "Why doesn't Capital flow from Rich to Poor Countries", American Economic Review $80(2)$.

Lucas, R. E. Jr. " On the mechanics of Economic Development", Journal of Monetary Economics, 22 (1988), 3-42

Mankiw, N.G., Romer, D., Weil, D.N. "A Contribution to the empirics of Economic Growth", Quarterly 
Journal of Economics, 107(2), May 1992, pp. 407438

Moore, R.E. "Measuring Inequality Change in an Economy with Income Growth", Jrnl of Dev Econ $32(1)$ Jan 1990

Moulin, H. and Thomson, W. "Can everyone benefit from growth?", Journal of Mathematical Economics 17 $(1988), 339-345$.

Pareto, V., Cours d'economique politique, Vol. 2 . Lausanne, 1897

Perroti, R. "Income Distribution, Politics and Growth", American Economic Review, 82(2), May 1992

Persson, T. and Tabellini, G. "Is Inequality Harmful for Growth?. Theory and evidence", NBER working paper 3599, January, 1991. (later appeared in the European Economic Review 36(4))

Ram, R. "Educational Expansion and Schooling. Inequality: INternational Evidence and Some Implications", Rev of Econ. and Stat. 72(2), May 1990

Ram, R. "Kuznets' Inverted U-hypothesis: Evidence from a highly developed country", Southern Economic Journal, 57(4), April 1991.

Rebelo, S. "Long-Run Policy Arialysis and Long-Run Growth", Journal of Political Economy 1991, 99(3).

Rivera-Bátiz, L. and Romer, P.M. "International Trade with Endogenous Tecnological Change", European Economic Review 35, 1991

Romer, P.M. "Are nonconvexities important for understanding Growth?", American Economic Review, 80 (2) 1990a.

Romer, P.M. "Endogenous Technological Change", Journal of Political Economy, $98(5), 1990 \mathrm{~b}$ 
Romer, P.M. "Increasing Returns and Long-Run Growth", Journal of Political Economy, 94 (October, 1986); $1002-37$.

Rosenzweig, M.R. "Population Growth and Human Capital Investments: Theory and Evidence", Journal of Political Economy 1990, 98(5).

Rustichini, A. and Schmitz, J.A. Jr. "Research and Imitation in long-run Growth", Journal of Monetary Econ. 27, 1991 .

Schettino, M. "Distribución del Ingreso y Economia Informal", mimeo, ITESM-CCM, 1992.

Schumpeter, J.A. "Teoría del Desenvolvimiento Económico", ECE México, 1944. Original Title: Theorie der Wirtschaftlichen Entwicklung, Verlag Dunker, 1912

Scott, M.G. "Policy Implications of 'A New View of Economic Growth'". The Economic Journal 102, May 1992

Segerstrom, P.S. "Innovation, Imitation and Economic Growth", Journal of Political Economy 1991, 99(4).

Sen, A. (ed.) "Economía del Crecimiento", Lecturas del Trimestre Económico 28, FCE, México, 1979. Title in English: Growth Theory, Penguin Books, 1970.

Sen, A. "Etica y Economía", Alianza-CNCA, México, 1992 .

Shannon, C. and Weaver, W., The Mathematical Theory of Communication, The University of Illinois Press, Urbana, 1949

Shaw, G.K. "Policy Implications of Endogenous Growth Theory", The Economic Journal, 102, May 1992.

Solow, R.M. Growth Theory. An Exposition. Oxford University Press, 1970.

Stokey, N. L. "Learning by doing and the Introduction of New Goods", Journal of Political Economy, $96(4), 1988$ 
Streeten, P., Burki, S.J., Haq, M.,Hicks, N., Stewart, F. First Things First. Meeting Basic Human Needs in the Developing Countries, World Bank, oxford University Press, 1981

summers, R. and Heston, A. "A new set of International Comparisons of Real Product and Price Levels Estimates for 130 countries, 19501985", The Review of Income and Wealth, Ser. 34, no. 1 March 1099

Summers, R. and Heston, A. "The Penn World Table (Mark 5): An Expanded Set of International comparisons, 1950-1988", Quarterly Journal of Economics, $106(2)$, May 1991

Sylos-Labini, P. The Forces of Economic Growth and Decline, MIT press, 1984.

Tamura, R. "Income Convergence in an Endogenous Growth Model", Journal of Political Economy 1991, 99(3)

Taubman, P. Sources of Inequality in Earnings, NorthHolland, Amsterdam, 1975

Wang, J.-Y. "Growth, Technology Transfer and the LongRun Thoery of International Capital Movements", Journal of International Econ. 29 (1990).

World Bank (1984) World Economic Outlook, World Bank, 1984

World Bank (1989) World Economic Outlook, World Bank, 1989

Yang, X. and Borland, J. "A Microeconomic Mechanism for Economic Growth", Journal of Political Economy 1991, 99(3).

Young, L. and Kim, G. "Education, Trade and Development", mimeo, University of Texas at Austin, 1992

Young, A. "Invention and Bounded Learning by Doing", Journal of Political Economy, 101(3), June 1993, pp. 443-472 
Yuhn, $\mathrm{K}-\mathrm{h}$ "Economic Growth, Technichal Change Biases and the Elasticity of Substitution: A test of the De La GrandVille Hypothesis", Rev. of Econ. and Stat. $73(2)$, May 1991

Yuhn, $\mathrm{K}-\mathrm{H}$ "Growth and Distribution, A test of the induced innovation Hypothesis for the Korean Economy", Applied Economics, 23(3), Mar 1991

Zilcha, I. "Efficiency in Economic Growth models under Uncertainty", Journal of Econ. Dyn. and Control 16 (1992) 